\title{
La construcción mediante amasado de barro en forma de bolas de Caramoro I (Elche, Alicante): Identificación de una nueva técnica constructiva con tierra en un asentamiento argárico
}

\section{The construction with cob balls of Caramoro I (Elche, Alicante): Identification of a new earth building technique in an Argaric settlement}

\author{
María Pastor Quiles* \\ Francisco Javier Jover Maestre ** \\ Sergio Martínez Monleón*** \\ Juan Antonio López Padilla****
}

Recibido: 16-01-2018

Aceptado: 12-09-2018

\section{Resumen}

En este artículo presentamos unas evidencias singulares de edificación con tierra, documentadas en el asentamiento del Bronce argárico de Caramoro I (Elche, Alicante), que muestran el empleo de una técnica constructiva prácticamente desconocida hasta la fecha en la Prehistoria de la península ibérica. En momentos avanzados de la ocupación del asentamiento fue empleado el amasado de barro en forma de bolas para remodelar y acondicionar una parte de las estructuras exteriores del enclave. La identificación de esta técnica constructiva con tierra adquiere especial interés dadas las dificultades presentes a la hora de distinguirla en el registro arqueológico de otras, como el empleo de adobes hechos a mano. De ahí la importancia de tratar de definir y diferenciar las distintas técnicas y contribuir así al correcto uso de la terminología de la arquitectura de tierra en su aplicación a las evidencias arqueológicas.

Palabras clave: Edad del Bronce; Cultura de El Argar; Construcción con tierra; Técnica constructiva; Amasado de bolas de barro; Adobe

* Departamento de Prehistoria, Arqueología, Historia Antigua, Filología griega y Filología latina. Universidad de Alicante,m.pastor@ua.es https://orcid.org/0000-00016112-6422

** Instituto Universitario de Investigación en Arqueología y Patrimonio Histórico. INAPH. Universidad de Alicante, javier.jover@ua.es https://orcid.org/0000-0001-52132361
*** Departamento de Prehistoria, Arqueología, Historia Antigua, Filología griega y Filología latina. Universidad de Alicante, sergio.mmonleon@ua.es, https://orcid.org/ 0000-0002-6352-4499

**** Museo Arqueológico Provincial de Alicante. MARQ, japadi@diputacionalicante.es https://orcid.org/00000002-1506-4731 


\begin{abstract}
In this article, we present some singular earth building remains documented in the Argaric Bronze Age settlement of Caramoro I (Elche, Alicante). These show the use of a construction technique almost unrecognised to date in the Prehistory of the Iberian Peninsula. Mud modelled in pieces, or cob balls, were used towards the end of the occupation of the site, to rebuild and coat part of some of the external walls. Identifying this technique is especially important due to the difficulties in distinguishing it in the archaeological record from others, such as hand-made adobe bricks. Therefore, it is crucial that we try to differentiate and define them, and to contribute to the correct use of earth building terminology applied to archaeological construction remains.
\end{abstract}

Keywords: Bronze Age; Argaric Culture; Earth building; Building technique; Cob balls; Mud brick

\section{INTRODUCCIÓN}

Las investigaciones arqueológicas sobre la Edad del Bronce en la península ibérica ya han superado el siglo y medio. La dedicación y el esfuerzo de numerosos investigadores e investigadoras han posibilitado disponer hoy de un considerable conocimiento sobre la evolución y características de la arquitectura implementada por las distintas sociedades que se gestaron y desarrollaron sobre el solar peninsular, siendo El Argar (Siret y Siret, 1890; Lull, 1983) una de las más relevantes y reconocidas. Las recientes excavaciones en grandes asentamientos como La Bastida (Totana, Murcia) (Lull et alii, 2014; 2015a; 2015b; entre otros) están mostrando la complejidad arquitectónica y la destacada inversión laboral efectuada en la construcción con mampostería de grandes infraestructuras defensivas e hidráulicas.

Sin embargo, en El Argar, al igual que en otras muchas sociedades contemporáneas, ni todas las edificaciones tuvieron un carácter monumental, ni la mampostería fue la única técnica empleada para levantarlas, sino que se emplearon con profusión otros materiales como la madera, el esparto, la caña y, sobre todo, la tierra, aplicándose diversas técnicas que a menudo se combinaban en una misma construcción. En este sentido, nuestro interés se centra aquí en presentar las características de unos restos constructivos particulares documentados en el asentamiento argárico de Caramoro I (Elche, Alicante) y abordar el análisis de la técnica de construcción en la que dichos materiales fueron empleados, el amasado de barro en forma de bolas y bloques. Hasta donde sabemos hoy, esta técnica se reconoce, describe y analiza aquí expresamente por primera vez en un yacimiento argárico, a pesar de que la construcción con tierra en este ámbito no ha carecido de atención (Ayala et alii, 1989; Rivera, 2007; 2011; Pastor, 2014; Lull et alii, 2015a; 2015c; entre otros).

La documentación, el análisis y la comparación de estos particulares restos constructivos con otros referentes arqueológicos y etnográficos permiten contribuir a la investigación y al conocimiento del empleo de la tierra en las actividades constructivas de la Prehistoria reciente de la península ibérica, tarea para cuyo adecuado desarrollo resulta imprescindible el manejo correcto de los términos definidos hasta hoy por distintos estudios, en relación a los materiales y técnicas de construcción. Por tanto, con este texto aspiramos a aportar no sólo nuevos datos, sino también un marco, a nivel tecnológico y terminológico, para los mismos.

\section{CaRamoro I: EMPlazamiento Y EXCAVACIONES ARQUEOLÓGICAS}

El yacimiento argárico de Caramoro I (Elche, Alicante) se ubica sobre un espolón rocoso en la margen izquierda del río Vinalopó, en el interior de un área natural conocida como Aigua Dolça i Salà, al norte del término municipal de Elche (Fig. 1). Como la mayoría de los asentamientos argáricos, ocupa un cerro o escarpe rocoso situado en las estribaciones de las sierras, separados de los llanos o vegas, pero con un amplio control visual sobre éstos, en lugares con buenas defensas naturales (Martínez Monleón, 2014: 58). Caramoro I está directamente edificado sobre un nivel de conglomerados compuesto de cantos redondeados, formado por calizas, areniscas, pequeños nódulos de sílex y, de forma accidental, rocas volcánicas unidas con carbonato cálcico, asociados con óxidos de hierro. Debajo de tales conglomerados aparece un nivel de margas arcillosas triásicas de coloración ocre-blanquecina. Este enclave se incluye dentro de un grupo de yacimientos de reducidas dimensiones -inferiores a $0,1 \mathrm{Ha}-$, que constituye el conjunto de poblados más numeroso dentro de la organización territorial argárica del Bajo Segura y Bajo Vinalopó y que se distribuyen preferentemente en las proximidades de otros enclaves de dimensiones superiores, aunque no en torno a los de mayor tamaño, compartiendo y complementando sus áreas de captación (Martínez Monleón, 2014).

Caramoro I fue excavado en primer lugar por R. Ramos Fernández en el año 1981 (Ramos, 1988). Tras las segundas excavaciones llevadas a cabo en el asentamiento, en 1989 y 1993, dirigidas por A. González Prats y E. Ruiz Segura, el yacimiento adoptó la denominación de Caramoro I, distinguiéndolo así del cercano enclave de Caramoro II (González y 


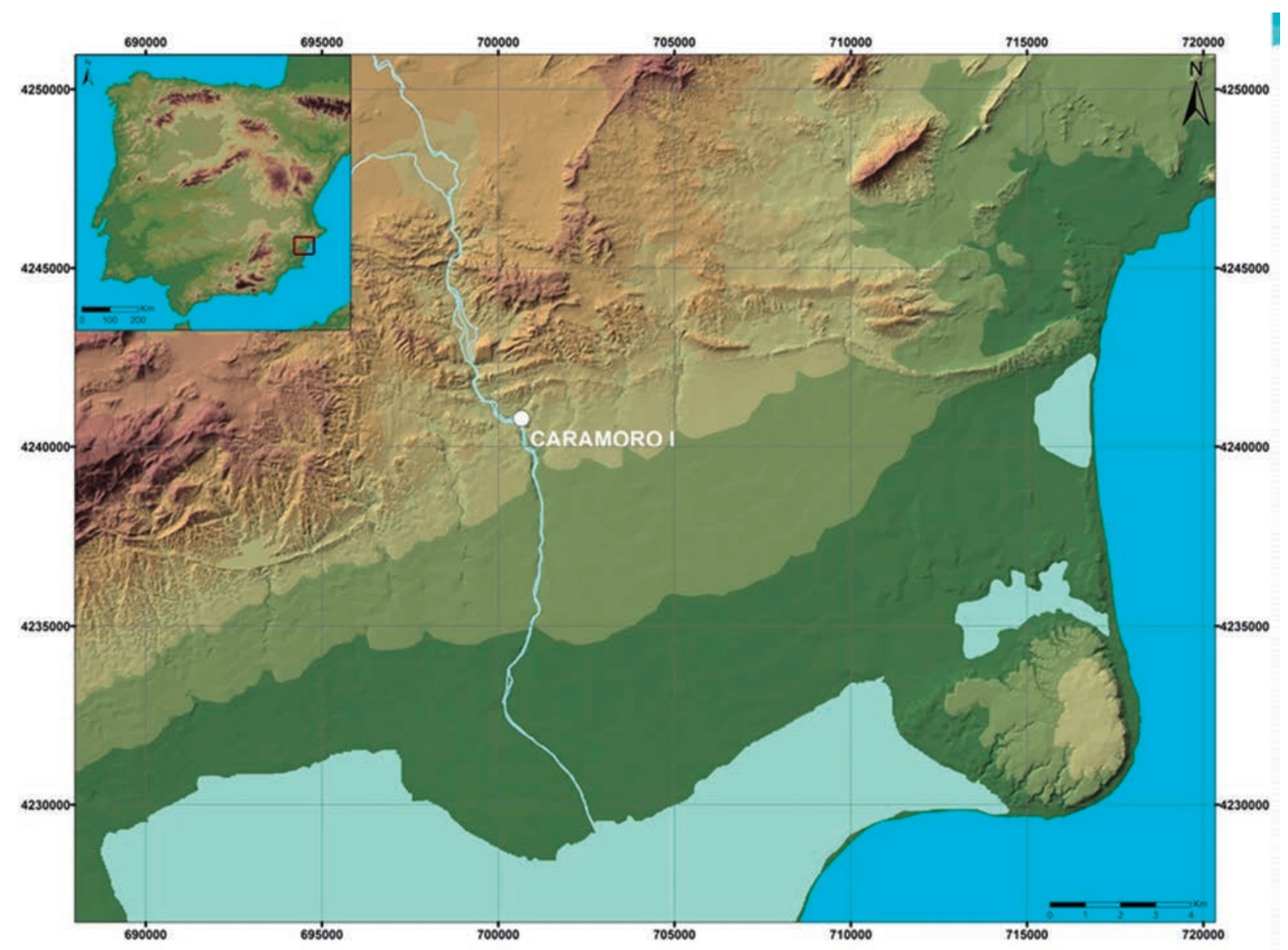

Figura 1. Ubicación del asentamiento argárico de Caramoro I.

Ruiz, 1992; García et alii, 2010), datado en el Bronce final. Estas intervenciones supusieron la excavación de casi la totalidad del yacimiento, con la excepción de dos pequeños testigos longitudinales - A y B- muy alterados, además de quedar a la intemperie las estructuras murarias documentadas. Estos trabajos permitieron publicar la planta del asentamiento, así como señalar la constatación de al menos dos pavimentaciones sucesivas en la denominada habitación A, la superposición de algunos tramos de muros o la determinación de un solo momento de ocupación en la zona del espacio E (Ramos, 1988; González y Ruiz, 1995). Las nuevas actuaciones arqueológicas ${ }^{1}$ desarrolladas en los años 2015 y 2016 han permitido documentar mejor la planimetría y establecer y datar las fases de ocupación.

La trama del asentamiento se configura a través de la construcción de un gran muro longitudinal -UE 2001-, asentado sobre la base geológica, que siguien-

1 Fueron llevadas a cabo bajo la dirección de F. J. Jover Maestre, S. Martínez Monleón, A. M. Álvarez Fortes y J. A. López Padilla y con la autorización de la Dirección General de Patrimonio de la Conselleria de Educación, Cultura y do las curvas de nivel se prolonga ligeramente de NO a SE a lo largo de algo más de $30 \mathrm{~m}$. Este muro de delimitación y cierre del asentamiento presenta una anchura media cercana a 1,10-1,20 m, aunque en el tercio más septentrional, justamente cuando la pendiente natural va aminorando, se va ensanchando hasta superar en algún punto los 2,50 m de anchura. En su zona septentrional el muro acaba de forma rectilínea, dejando un espacio de algo más de $4 \mathrm{~m}$ hasta el arranque de la pendiente. Este espacio constituye el único acceso al poblado. Como refuerzo de este muro, especialmente en su extremo central y meridional, en el punto donde reduce su anchura, se construyó y adosó un gran antemural -UE 2000- apoyado sobre un relleno de margas verdes muy compactas -UE 1813- que a su vez se apoyan en el muro 2001, dispuesto a modo de refuerzo. En sí, el antemural 2000 es un muro de aterrazamiento ataludado de distinta anchura, que conserva algo más de $2 \mathrm{~m}$ de altu-

Deporte de la Generalitat Valenciana. Expts. 2015/0305-A (SS.TT.: A-2015-109) y 2016/0315-A (SS.TT: A-2015109). 
ra y casi $4 \mathrm{~m}$ anchura en la zona meridional, precisamente donde el muro 2001 hace una mayor inflexión y la pendiente es mayor. Así, el muro de cierre -UE 2001- solamente permite un acceso al interior del asentamiento por su lado nororiental, delimitando una superficie útil de casi $420 \mathrm{~m}^{2}$, en la que se construyeron diversas estancias. Los espacios definidos son los denominados como A, B, C, E e I. Se ha determinado un primer momento de construcción y dos momentos sucesivos de remodelación constructiva (Fig. 2).

Estas nuevas actuaciones también han posibilitado emprender el estudio de los numerosos restos documentados a lo largo de las distintas intervenciones. Entre otros aspectos de importancia, estos últimos trabajos han permitido abordar en profundidad una cuestión cuya presencia ya fue advertida en el enclave por parte de A. González Prats y E. Ruiz Segura hace más de dos décadas, pero que hasta la fecha no ha sido objeto de investigación. Se trata de una serie de materiales de tierra, de formas esferoides y oblongas de variadas dimensiones, que habrían contribuido a conformar una parte de las estructuras extramuros del poblado, ubicadas en su límite oriental, en el llamado "bastión" o espacio H y su unión meridional al espacio G y al antemural UE 2000 (Fig. 3).

\section{Las Evidencias Materiales}

Las edificaciones del asentamiento de Caramoro I conforman una serie de espacios que parecen vertebrarse en torno a un muro de considerable envergadura-UE 2001- que sirve de cierre para todo el espacio habitado, y están constituidas, prácticamente en su totalidad, por muros de mampostería. Para el acondicionamiento y el remate de las estructuras se habrían empleado otros materiales constructivos, como la tierra y materia vegetal de distinto tipo. Durante las excavaciones realizadas en 1989 y 1993 fueron documentadas las técnicas y materiales constructivos utilizados en el asentamiento, haciéndose referencia a que los alzados de las edificaciones habrían sido levantados con piedra y barro y después revestidos con arcilla de coloración amarilla. Asimismo, se apuntaba que la parte oriental del llamado bastión $\mathrm{H}$ se habría erigido con piedras de gran tamaño y "adobes planoconvexos elaborados con barro y esparto, en

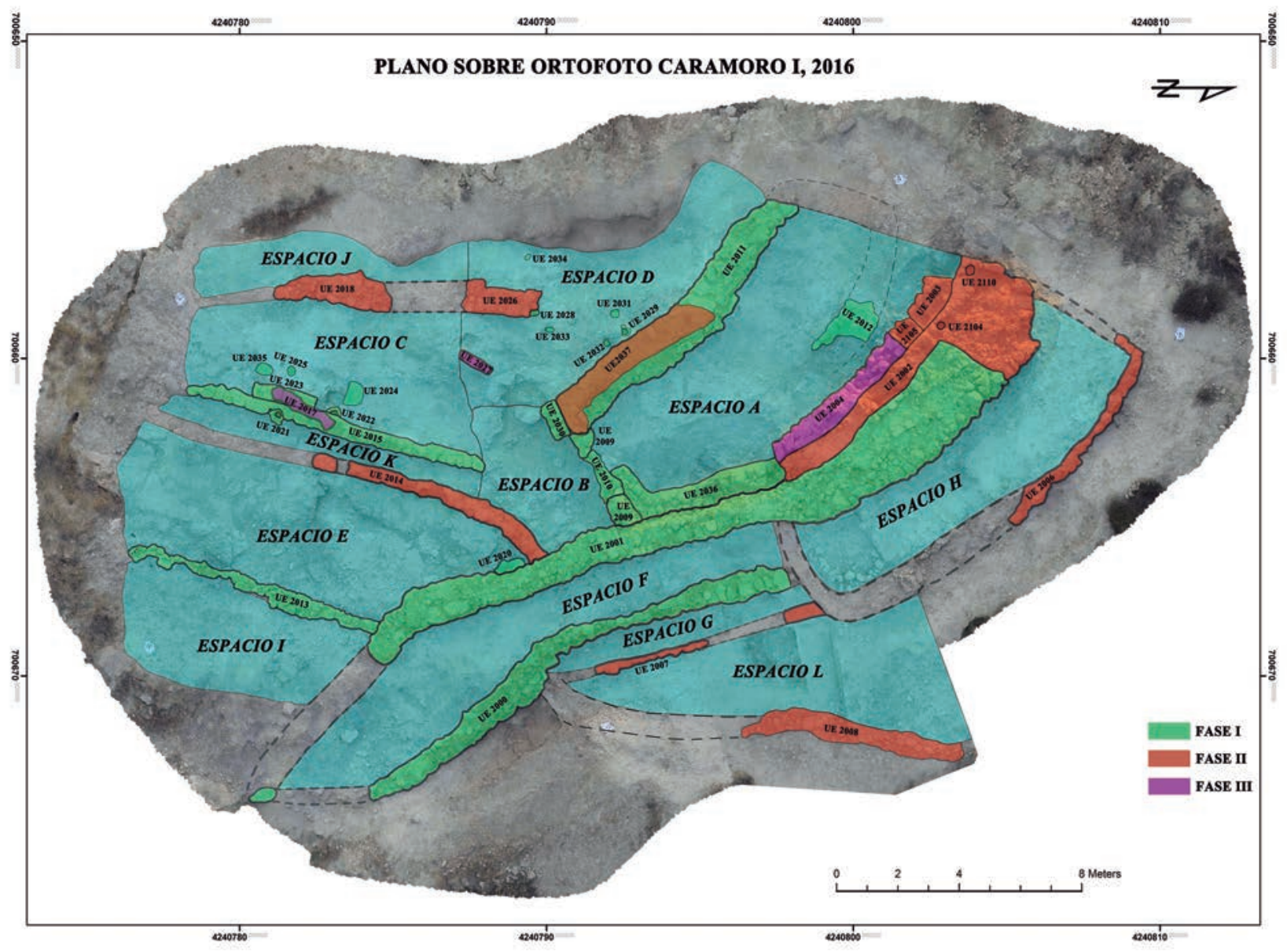

Figura 2. Planimetría con indicación de las fases de construcción y remodelación en el asentamiento. La fase I corresponde al momento inicial de construcción del asentamiento. Las fases II y III son remodelaciones efectuadas sobre la construcción inicial. 


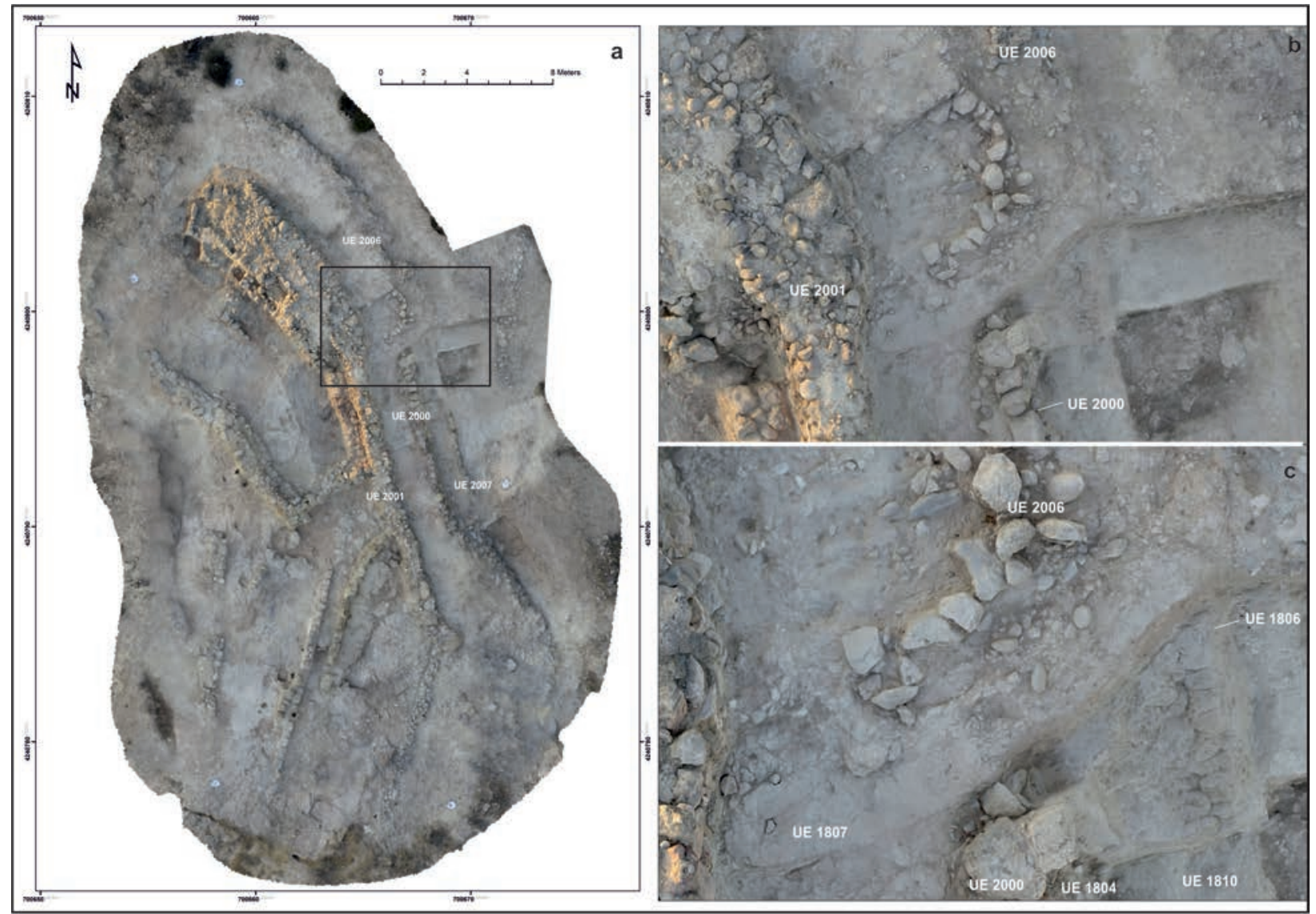

Figura 3. a. Ortofoto de la planta del asentamiento, con indicación de la zona oriental extramuros donde se ubican los restos de construcciones de tierra y de las principales unidades estructurales asociadas. b. Visión ampliada de este espacio, donde se aprecia el cierre curvo del espacio H en su unión con el muro UE 2001 y su relación con el antemural UE 2000. c. Detalle de esta área, en el que se aprecia el refuerzo de tierra de la plataforma curva y el tramo de amasado de barro en forma de bloques UE 1806.

los que hoy se aprecian claramente las improntas de las hebras vegetales" (González y Ruiz, 1995: 87$90)^{2}$. La presencia de estos materiales fue representada gráficamente en un plano del asentamiento, con dos hileras de estas piezas en el cierre suroriental del bastión H (Fig. 4). Este espacio H habría sido configurado durante la primera de las remodelaciones arquitectónicas y de mantenimiento acontecidas en Caramoro I, en especial en su zona de acceso.

En el marco de las actuaciones llevadas a cabo en 2015 y 2016 se pudieron reconocer varias remodelaciones en el asentamiento - demarcarían, al menos, tres momentos de uso sucesivos- que implicaron, sobre la planta inicial, diversas ampliaciones y reacondicionamientos. Mientras que el antemural UE 2000 fue levantado en el momento inicial de construcción, datado hacia los inicios del II milenio cal BC, el bastión o espacio H o UE 2006 habría sido un añadido posterior, efectuado en relación con la primera de las remodela-

2 Aunque estos materiales fueron publicados como "adobes" (González y Ruiz, 1995: 87-90), en el diario de excavación inédito, elaborado por Elisa Ruiz Segura, la técnica ya fue ciones efectuadas, habiendo transcurrido, con toda probabilidad, un escaso periodo temporal entre ambos. La zona de conexión de ambas estructuras fue mantenida y reacondicionada a lo largo del tiempo, siendo la segunda y tercera de las remodelaciones a las que corresponderían probablemente los restos de la construcción de tierra UE 1806, ligeramente ataludada, de cierre del espacio $\mathrm{G}$ y de refuerzo de la zona de conexión con el antemural a los que hacemos referencia en este texto.

Así, por un lado, procedentes del realzado y acondicionamiento del cierre oriental del bastión $\mathrm{H}$ o UE 2006, hemos podido documentar un buen número de piezas de barro a las que aludían A. González Prats y E. Ruiz Segura, tanto completas, como fragmentos de ellas, de forma esferoide en su mayoría, con improntas en sus superficies de material vegetal con el que se habrían amasado y configurado las unidades de barro (Fig. 5).

identificada, ya que puede leerse: "no podemos hablar de adobes por cuanto las pellas se superponen estando frescas aún, por lo que la de arriba adopta la forma de la inferior". 


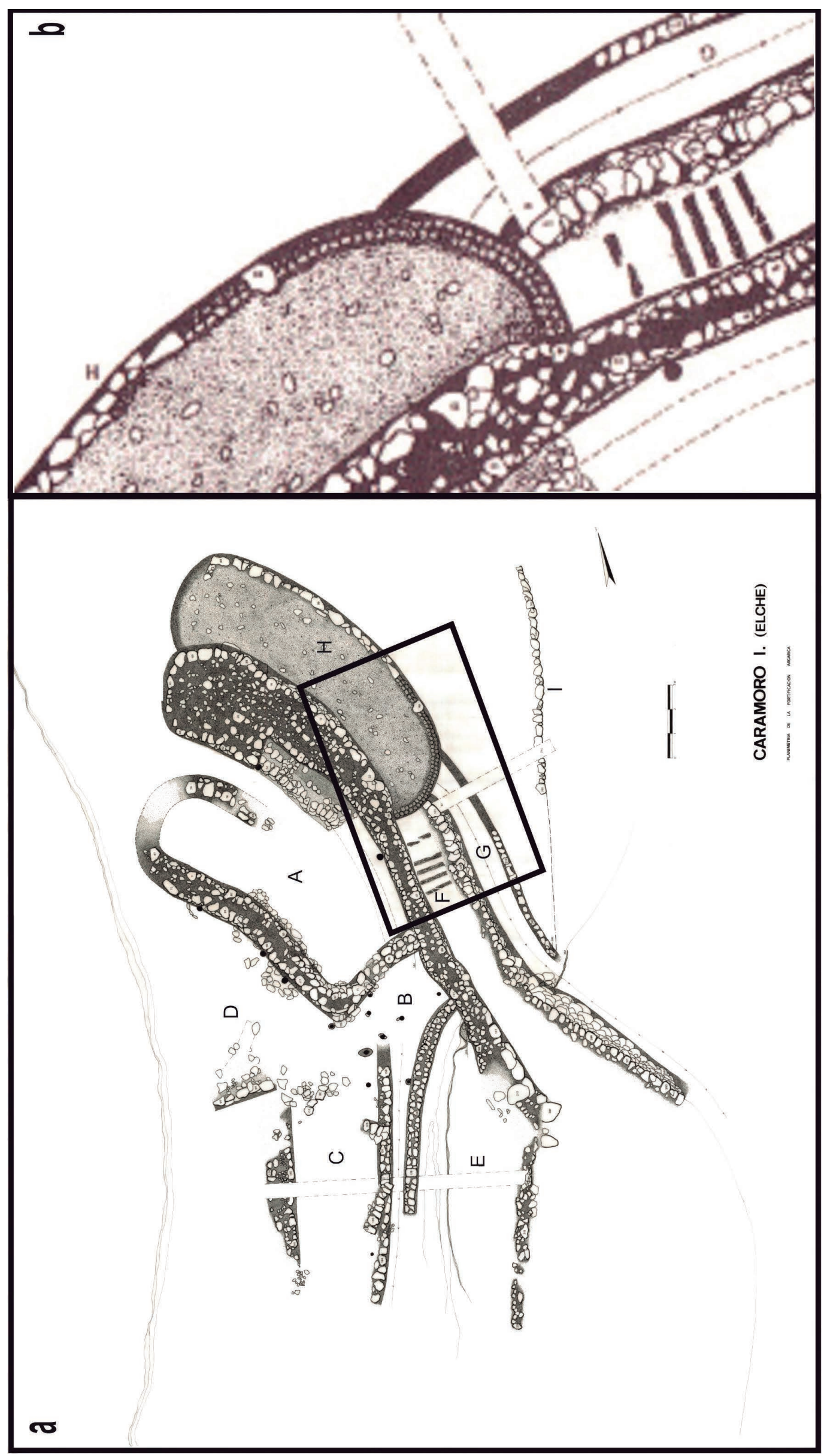

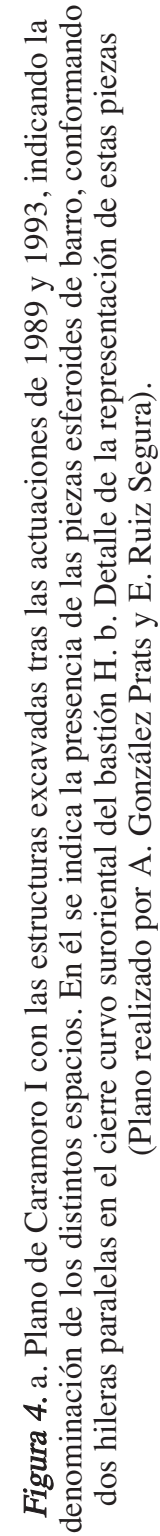




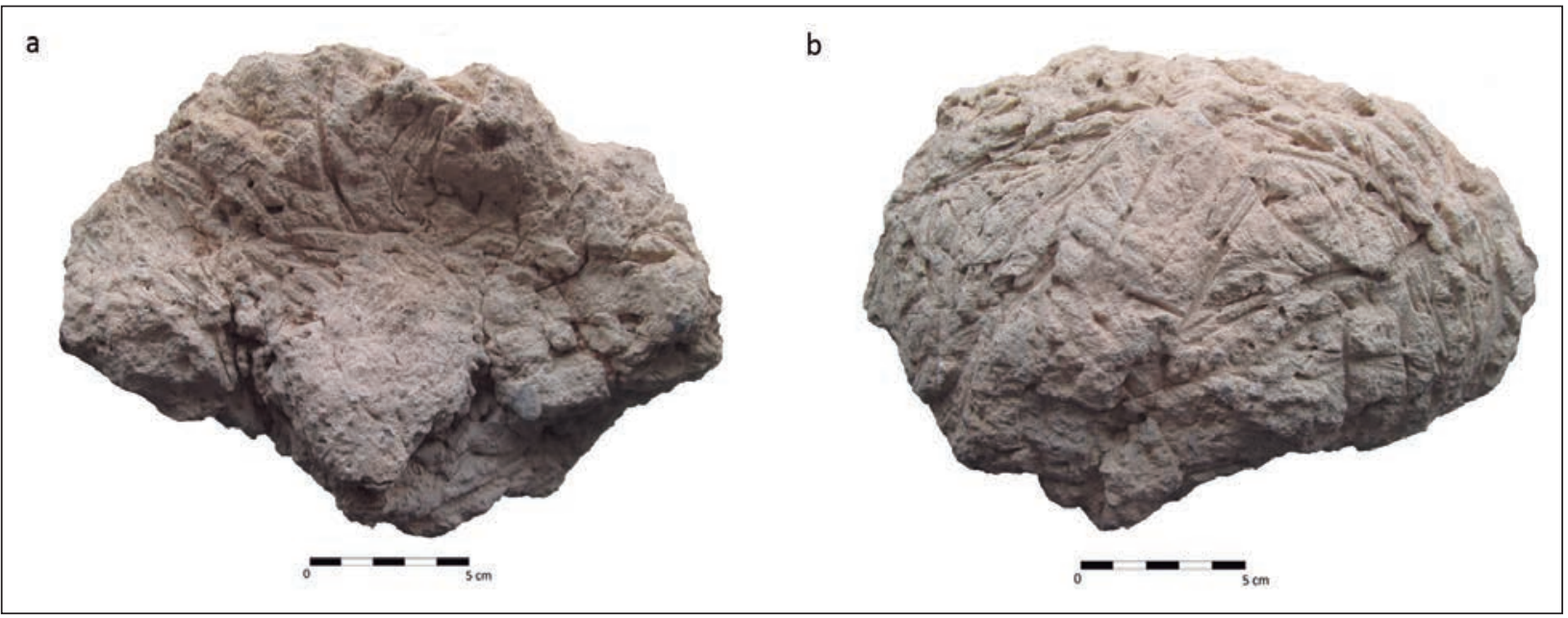

Figura 5. Fotografía de ambas caras de uno de los elementos de barro hallados en superficie. a. Cara que presenta un rehundimiento central. b. Cara contraria de superficie convexa.

Estas piezas han sido identificadas, tanto entre los materiales constructivos de tierra procedentes de las excavaciones en Caramoro I de 1989, conservados en el Museo Arqueológico y de Historia de Elche (MAHE) - 86 elementos, asociados al bastión $\mathrm{H}$, en el sector D-, como todavía presentes en superficie en el propio asentamiento, en su mayoría fuera de su posición original y no formando parte ya de un elemento estructural -13 piezas estudiadas-. A ello se unen otros siete ejemplares completos o fragmentos de ellos, recuperados durante la excavación del año 2016. Especialmente en el caso de los restos hallados en superficie, estos materiales mostraban un grado de endurecimiento muy alto y una coloración marrón claro, con manchas blanquecinas y parcialmente anaranjadas en algún caso. Las improntas presentes en las piezas de elementos vegetales añadidos al amasado de barro, de considerable longitud y de tipo paja o tallo, de reducido calibre, han sido ocupadas por raíces en muchos de los ejemplares, algo que también pudo observarse in situ durante las excavaciones en el asentamiento.
En estos materiales constructivos, con unas dimensiones variables, se ha observado a nivel macroscópico en la composición de los morteros de barro la presencia de piedras, en algunos casos de considerable tamaño -hasta $6 \mathrm{~cm}$ de longitud-, así como de carbones, malacofauna $\mathrm{y}$, ocasionalmente, hueso quemado $\mathrm{y}$ agregados de ceniza (Fig. 6).

De este modo, el espacio $\mathrm{H}$, constituido por la plataforma UE 2006, habría estado configurado en su extremo meridional, a partir de un determinado momento, por un alzado constituido por piezas de barro amasado. La plataforma habría sido edificada mediante bloques pétreos de diverso tamaño y tierra, formando una planta de tendencia rectangular-irregular con unas dimensiones máximas de $12,90 \mathrm{~m}$ en el eje SE-NO y 2,95 m en el eje NE-SO, delimitando un área aproximada de $33,65 \mathrm{~m}^{2}$. Esta construcción se habría elevado sobre una base de tierra, que adoptaba la misma forma curva (Fig. 7a), con un ancho de $0,45 \mathrm{~m}$. Las formas aproximadamente esferoides de barro empleadas en esta plataforma estaban revestidas por un amasado de tierra extendida -UE 1807- de similares características.

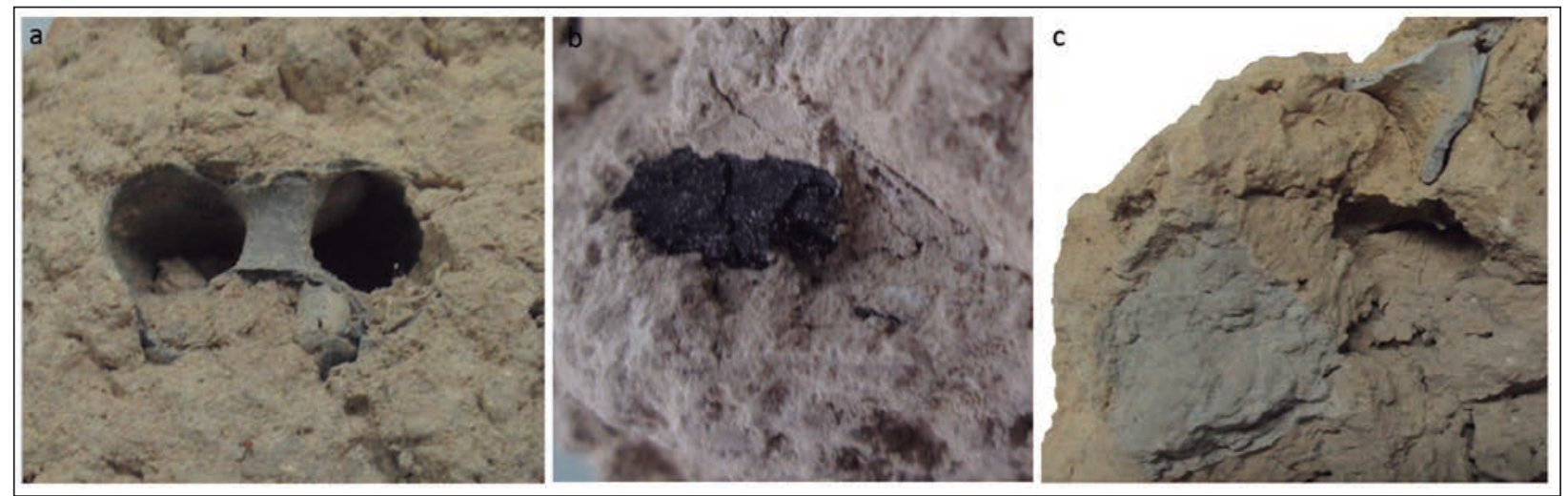

Figura 6. Elementos contenidos en los morteros que conforman las piezas de barro esferoides: a. malacofauna. b. madera carbonizada. c. hueso calcinado y ceniza. 
Por otro lado, durante la campaña de excavación de 2016, a muy escasa distancia de esta construcción y en la zona de conexión entre el extremo oriental del bastión o UE 2006 y el arranque del antemural 2000, se excavó un nuevo tramo de alzado de barro ligeramente ataludado -UE 1806- (Fig. 7b), dispuesto con una orientación noroeste-sureste, posiblemente a modo de refuerzo de ambas construcciones, que habría sido construido con una técnica basada en la aplicación manual de elementos de barro de forma oblonga hechos igualmente a mano, a partir de una mezcla de barro y materia vegetal también de considerable longitud y de tipo paja o tallo. Esta técnica constructiva podemos considerarla muy similar a la que habrían conformado las piezas de forma más o menos esférica en los alzados del bastión, y en la caracterización de esta técnica nos centraremos más adelante. Este resto de alzado documentado presentaba unas dimensiones de 0,36 m de ancho en su extremo septentrional y 0,28 $\mathrm{m}$ en el más meridional y su longitud excavada ha sido de 1,30 m de largo en su cara oriental y exterior y 1,05 $\mathrm{m}$ en su cara interior. El tramo de muro de bloques de barro se localizó tras excavar el llamado testigo B -dejado en reserva en las excavaciones practicadas por A. González y E. Ruiz- de la zona 3, entre el espacio $\mathrm{H}$, al norte, y los espacios $\mathrm{F}$ y $\mathrm{G}$ hacia su extremo meridional, a su vez separados por el antemural UE 2000. La orientación de este tramo de amasado de barro dispuesto en forma de elementos de forma oblonga parece conectar con el muro UE 2007, que cierra el espacio $\mathrm{G}$ en su lateral oriental. Se adosa a una unidad de sedimento blanquecino muy compacto, de unos 15-20 $\mathrm{cm}$ de grosor en talud y 1,36 $\mathrm{m}$ de altura, que interpretamos como un enfoscado del muro UE 2000 en su extremo septentrional -UE 1804-, conservado bajo el testigo B. A su vez, al tramo de alzado de amasado de barro en forma de piezas oblongas se le adosa, en el lateral contrario al ocupado por este grueso revestimiento, el pavimento UE 1810, asociado a la remodelación final del poblado.

No contamos con dataciones absolutas para el espacio externo del asentamiento donde se ubican las construcciones a las que nos referimos. Pero sí disponemos de ellas para la remodelación del espacio D. Procedente de un relleno sedimentario -UE 1503contenido entre dos muros construidos en distintos momentos de uso del espacio D, fue seleccionada una muestra de vida de corta -tibia de ovicaprino-, que ha aportado una fecha media en torno al $1850 \mathrm{cal} \mathrm{BC}$ (Beta-464793: $3550 \pm 30$ BP/2009-1772 cal BC $-2 \sigma_{-}^{-3}$ ). Si tenemos en cuenta que la construcción del primer pavimento de este mismo espacio no es mucho más antigua, también datado sobre un fragmento distal de tibia de ovicaprino (Beta-419055: $3570 \pm 30$

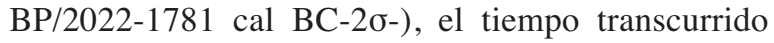
debió ser breve.

Por su parte, el estudio macroscópico individualizado de una de las piezas oblongas que constituían este tramo de alzado de barro (Fig. 8a), que presentaba unas dimensiones de $23 \times 16 \times 9 \mathrm{~cm}$, coloración marrón verdosa y un grado medio de endurecimiento, ha determinado que en la composición del mortero estaban contenidos, además de guijarros de hasta 2,5 cm de largo, restos de carbón. Es destacable la presencia de una
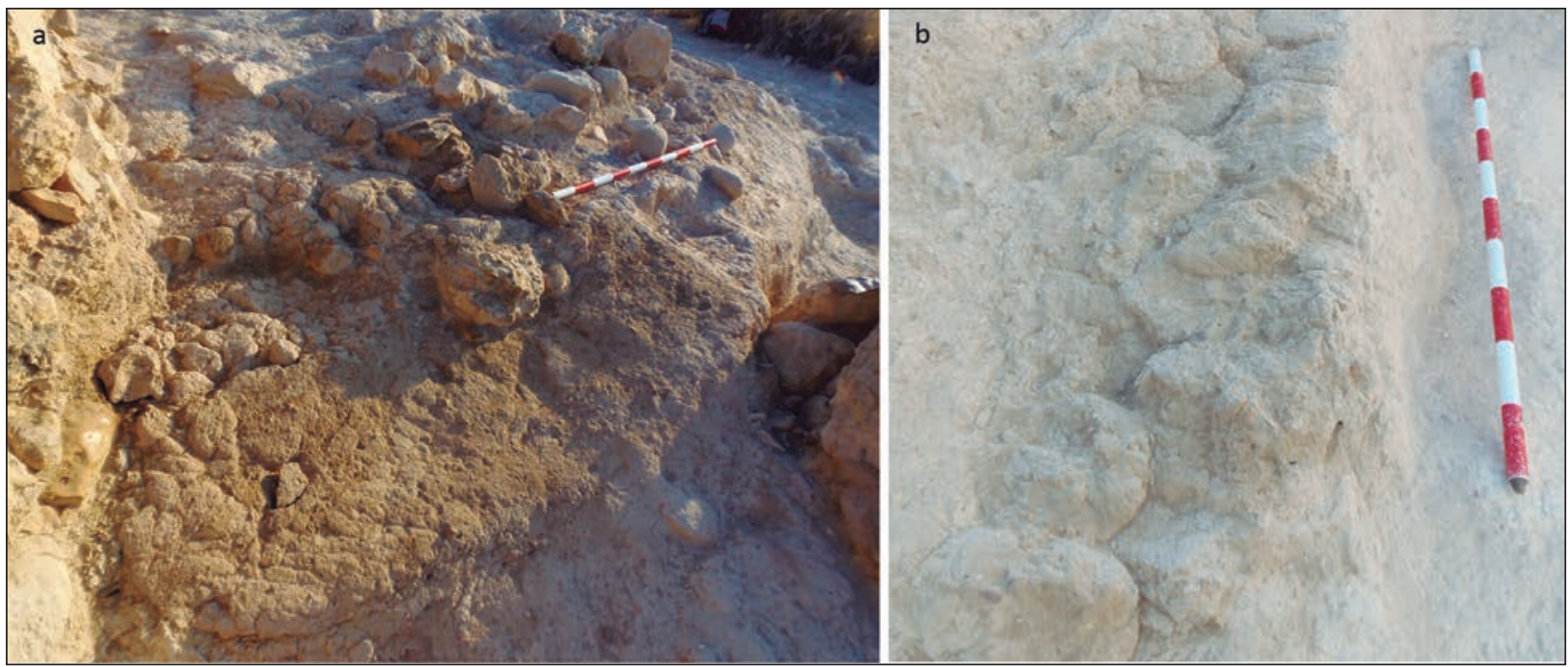

Figura 7. a. Vista del refuerzo curvo de tierra UE 1807 desde su extremo meridional. Sobre él se habrían colocado las piezas semiesféricas. b. Tramo de alzado de barro construido mediante la disposición de elementos de forma oblonga en estado húmedo, visto desde su extremo meridional.

3 Las fechas calibradas se presentan con el $95 \%$ de probabilidad utilizando el programa OxCal v.4.2.3 (Bronk Ramsey,
2009), según la curva atmosférica IntCal13 (Reimer et al. 2013). 
impronta de cuerda trenzada (Fig. 8b y c) en la superficie de esta pieza. En un principio, pensamos que esta impronta podía ser un indicador de la reutilización de materiales, pero en el diario de la excavación inédito de 1989 se asocian las cuerdas a la propia conformación de estas estructuras de barro. Se apunta que las cuerdas contribuirían a la consistencia de las estructuras al mejorar la unión entre las distintas unidades, basándose en la observación de improntas de cuerdas "en el relleno de la parte inferior de la muralla". De ser así, estaríamos ante un ejemplo de introducción en estructuras de amasado de barro de cuerdas de fibras vegetales con una función constructiva, como la de conseguir una unión más sólida entre los distintos elementos que la forman. El empleo de cuerdas trenzadas en otras partes de las edificaciones de Caramoro I ha sido documentado en un fragmento de barro procedente de la UE 2101, asociado a improntas de cañas, a modo de atadura, que podría haber pertenecido a una techumbre. No obstante, otros materiales que formaban parte de los morteros de las formas esferoides mencionados más arriba -restos de ceniza, carbones, hueso calcinado-, sí parecen indicar la reutilización de sedimentos o desechos en la elaboración de estos elementos. El reaprovechamiento de restos constructivos de tierra en la elaboración de nuevas construcciones se ha evidenciado igualmente durante el análisis macroscópico de los elementos de barro endurecido asociados a las edificaciones del asentamiento. El caso más evidente es el de una pieza de barro endurecido localizada en la UE 2101, en cuyo interior se hallaba incluido otro fragmento constructivo de menor tamaño, endurecido en mayor medida y con improntas constructivas de carrizo, que habría sido incorporado probablemente durante el proceso de fabricación de un nuevo mortero de barro.

Como describiremos a continuación, consideramos que los elementos constructivos de barro objeto de este trabajo habrían sido colocados todavía en estado húmedo en el momento de erigir los alzados, sin haber sido secados previamente. Como argumento clave que refuerza esta hipótesis, basándonos en la

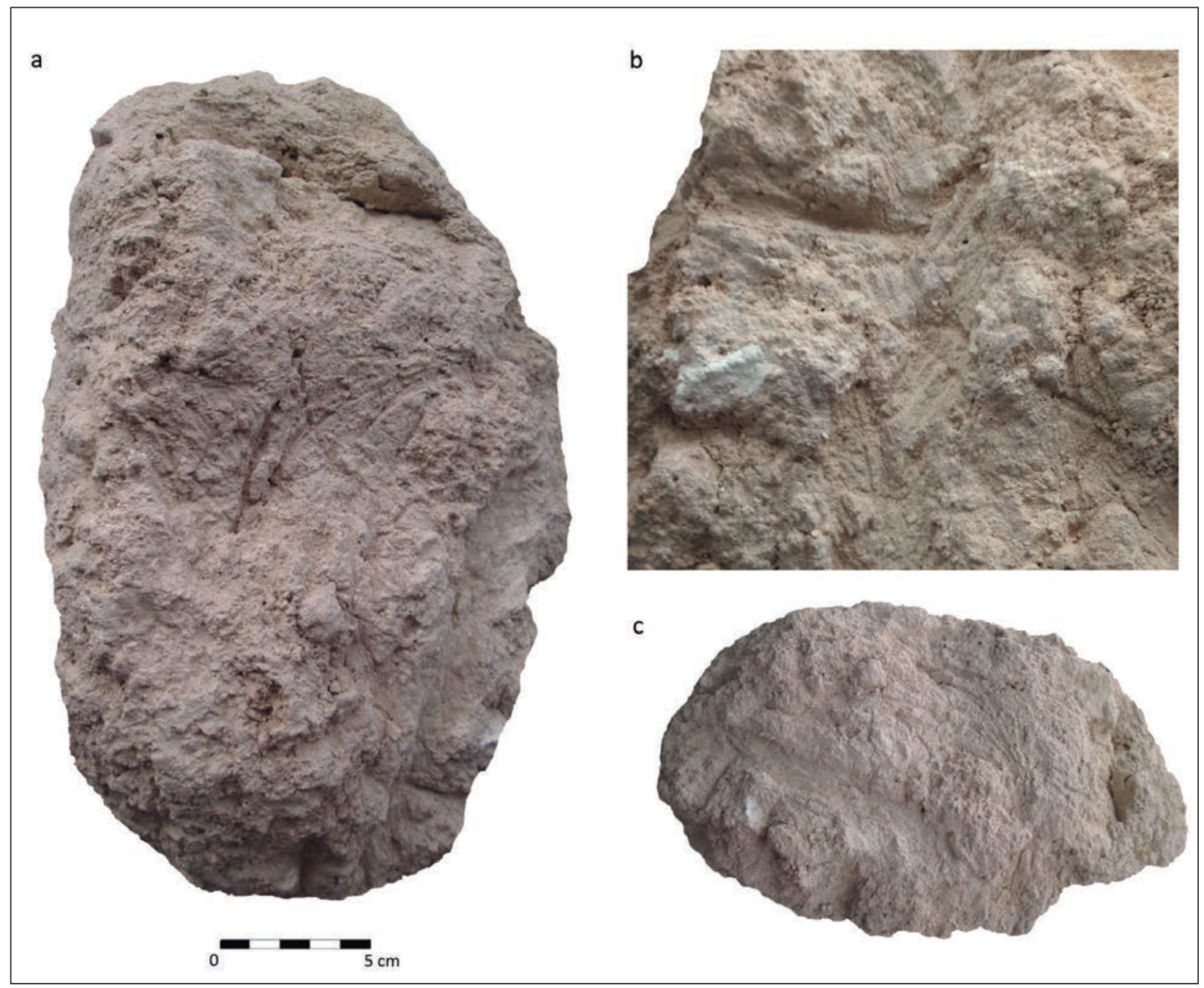

Figura 8. a. Elemento de barro de forma oblonga extraído del tramo de alzado excavado en 2016.

b. Detalle de la impronta de cuerda trenzada visible en uno de sus laterales.

c. Vista frontal del lateral de la pieza con el surco impreso dejado por la cuerda. 
morfología de los ejemplares individualizados, encontramos el hecho de que sus superficies curvas presenten rehundimientos en prácticamente todos los casos (Fig. 9a) y, en general, formas esferoides u oblongas aplastadas, resultado de haber sido colocadas unas sobre y junto a otras durante el proceso constructivo. Por su parte, respecto al tramo de muro levantado con las piezas de forma oblonga, ha sido la propia excavación arqueológica del mismo la que ha permitido distinguir que se trataba de una aplicación de formas amasadas y aplicadas en estado húmedo unas junto y sobre otras (Fig. 7b).

Esta técnica pudo haberse empleado en otros poblados de la Prehistoria reciente del sudeste o de otras zonas de la península ibérica, también con anterioridad al período argárico, pero su presencia en el ámbito de El Argar no ha sido recogida explícitamente hasta ahora en la bibliografía (Ayala y Ortiz, 1989; Ayala et alii, 1989; Rivera, 2007; 2009; 2011; Martínez Mira et alii, 2014; Pastor 2014; 2017). A este respecto, consideramos que es posible que esta técnica se hubiera utilizado también en alguna de las estructuras que se edificaron en el asentamiento de Laderas del Castillo (Callosa de Segura, Alicante), dado que en este yacimiento hemos recuperado 14 restos de material constructivo de barro cuya morfología es muy similar a la de las piezas recuperadas en Caramoro I (Fig. 10). Estos fragmentos han sido hallados tanto en superficie como en contextos datados a inicios del II milenio cal BC -UE 31005, derrumbe del Conjunto Estructural A-.
De igual modo, en el poblado del Bronce medio de Hoya Quemada (Mora de Rubielos, Teruel), parecen haberse documentado dos tramos de alzados construidos con esta misma técnica, con un "amasado de arcilla, agua y paja... colocando unas pellas de barro unas sobre otras" (Burillo y Picazo, 1986: 10). Fuera del ámbito de la península ibérica, han sido registradas construcciones realizadas con amasados de barro tanto en yacimientos neolíticos, como Klimonas (Ayios Tychonas, Chipre) (Mylona et alii, 2017: 112), como en el asentamiento de mediados del III milenio cal BC de La Capoulière (Mauguio, Francia) (Wattez, 2003: 208-210; Gutherz et alii, 2008: 426).

\section{DISCUSIÓN: SOBRE LA TÉCNICA CONSTRUCTIVA EMPLEADA}

A la hora de determinar la técnica constructiva mediante la que fueron producidas y colocadas estas piezas de barro empleadas como material constructivo, una cuestión de importancia es el hecho de que hubieran sido puestas en obra en estado húmedo unas junto a otras, o ya completamente secas. En el primero de los casos, estaríamos ante la técnica que se conoce como amasado de barro, mientras que, si hubiesen sido aplicadas tras haber sido secadas previamente, se trataría de adobes (Sánchez, 1997; 1999; Minke, 2001; De Chazelles y Klein, 2003; Wright, 2009; entre otros), que son unidos generalmente entre sí por mortero. En el caso de Caramoro I, tanto las bolas documentadas en su posición original, como las preservadas de forma

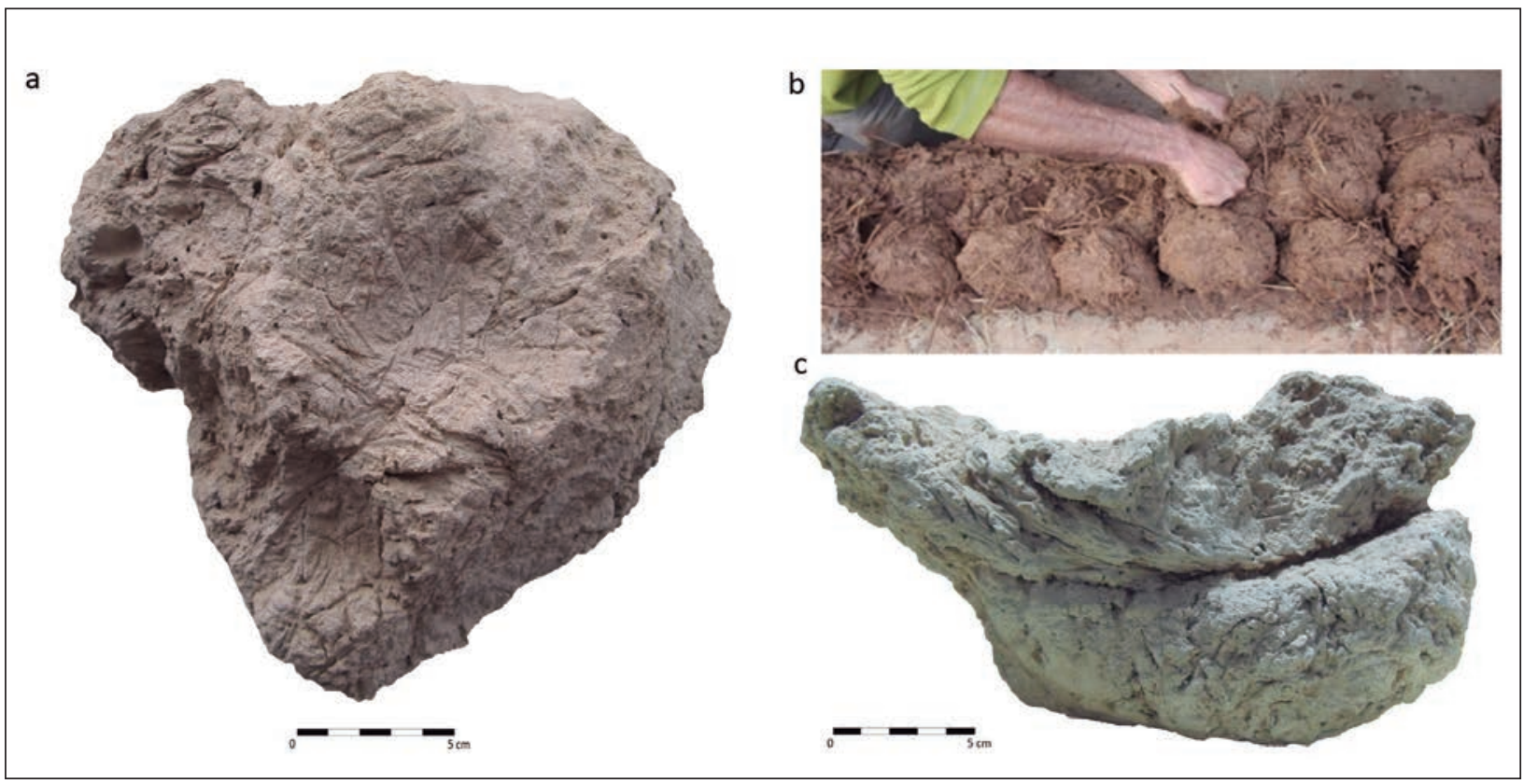

Figura 9. a. Pieza de barro recuperada en la campaña de excavación de 2016, mostrando diversos rehundimientos en su superficie, resultado de la superposición de elementos constructivos durante su puesta en obra.

b. Ejemplo de construcción actual mediante amasado de barro en forma de bolas (Perello, 2015: 3, Fig. 5). c. Vista lateral de una de las piezas de barro recuperadas en 1989, donde se aprecia la superposición de dos de ellas. 


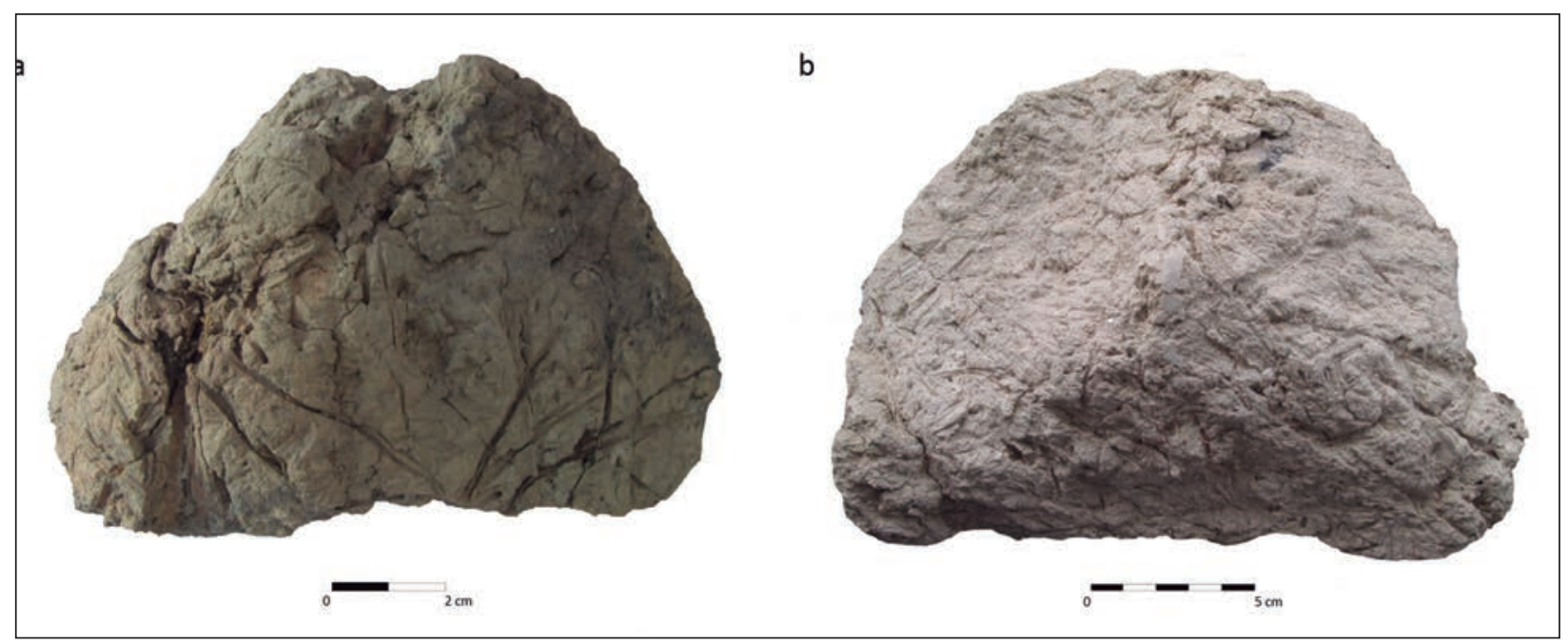

Figura 10. a. Pieza de barro localizada en superficie en el asentamiento de Laderas del Castillo (Callosa de Segura, Alicante).

b. Elemento constructivo de amasado de barro recuperado en Caramoro I durante las excavaciones de 2016.

individualizada y descontextualizada, fueron dispuestas en la edificación en estado todavía húmedo, al presentar muchas de ellas señales de aplastamiento o rehundimiento en algunos de sus lados o caras, tratándose, por tanto, de la técnica conocida como amasado o tierra modelada ${ }^{4}$.

En este tipo de técnica constructiva es frecuente que, a la hora de aplicar el barro húmedo a los muros, éste se modele en forma de bolas o pequeños bloques, que después se pueden modelar nuevamente y regularizar ya dispuestos en la estructura, disimulándose la forma en la que se ha aplicado el barro inicialmente y obteniendo la apariencia de un muro monolítico (Fig. 11). Estas piezas de barro se conocen como pains o galettes de terre en francés (De Chazelles, 2006; Klein, 2003), en alemán Lehmbrote, Lehmkugeln o Lehmpatzen, y en el mundo anglosajón como puddled mud block (Baloi, 2001), cob bricks o cob balls, aunque también es relativamente frecuente en la bibliografía que la denominación de cob se refiera al empleo del barro directamente en bolas y no de forma irregular (Houben y Guillaud, 1993: 4; Minke, 2001; Mileto et alii, 2011; entre otros).

A nivel etnográfico, esta técnica se documenta en diferentes lugares de África (Guidoni, 1977: 250; Agorsah, 1985: 105, Fig 2; Baloi, 2011: 51) y Asia, por ejemplo en Yemen, donde se denomina zabur (Wright, 2009: 569). Algunos ejemplos de muros realizados con estos módulos de barro en estado húmedo, de cronolo-

4 En francés es denominada como façonnage direct o bauge (De Chazelles, 2006; Patte y Streiff, 2006), massone en Italia (Achenza y Sanna, 2008: 30), terra empilhada en portugués (Correia, 2006: 16), Lagenlehm en Alemania (Minke, 2001: 88-90; Knoll y Klamm, 2015), y shaped gías recientes -entre los siglos XVIII-XX-, han sido documentados en Bélgica (Bavay, 2006: 114), Francia (Klein, 2003: 432-435; Bardel y Rioult, 2006: 169), así como en Alemania (Güntzel, 1986: 123, 369; Volkskundliche Kommission für Thüringen e.V, 2009: 33) y la República checa (Syrova y Syrovy, 2006: 130). Asimismo, la construcción de alzados con elementos de barro, moldeados a mano y de forma esferoide, se reconoce como una técnica tradicional de construcción con tierra en Argentina (Rotondaro, 2004: 20), y entendemos que, aunque no se menciona explícitamente, el autor debe referirse al empleo de estas piezas en estado húmedo y no endurecidas.

En la técnica del amasado, el barro se aplica directamente en estado húmedo, con las manos o con un instrumento, a veces lanzándolo, y se regulariza para obtener superficies exteriores lisas, en ocasiones mediante golpes con una tabla de madera, como en el caso del cob inglés. El lanzado o aplastado del barro se relaciona con la obtención de una mayor compactación y resistencia del mortero, ya que la unión del material se realiza mediante estos procesos mecánicos (Minke, 2001: 73, 87). No obstante, también puede estar relacionado con la agilización del proceso constructivo durante la puesta en obra del material, algo que los elementos de barro húmedo permiten, pero no las piezas ya secas y prefabricadas, que generalmente son colocados de forma ordenada entre capas de mortero. Así, el barro puede modelarse en forma de bolas por una

earth, stacked earth (Houben y Guillaud, 1993: 164) o cob (Keefe, 2005) en inglés, término que también hace referencia al propio material. También se conoce como tauf en árabe, chineh en persa (Aurenche, 1981: 54), y pakhsa en Afganistán (Scherrer, 2003). 
a
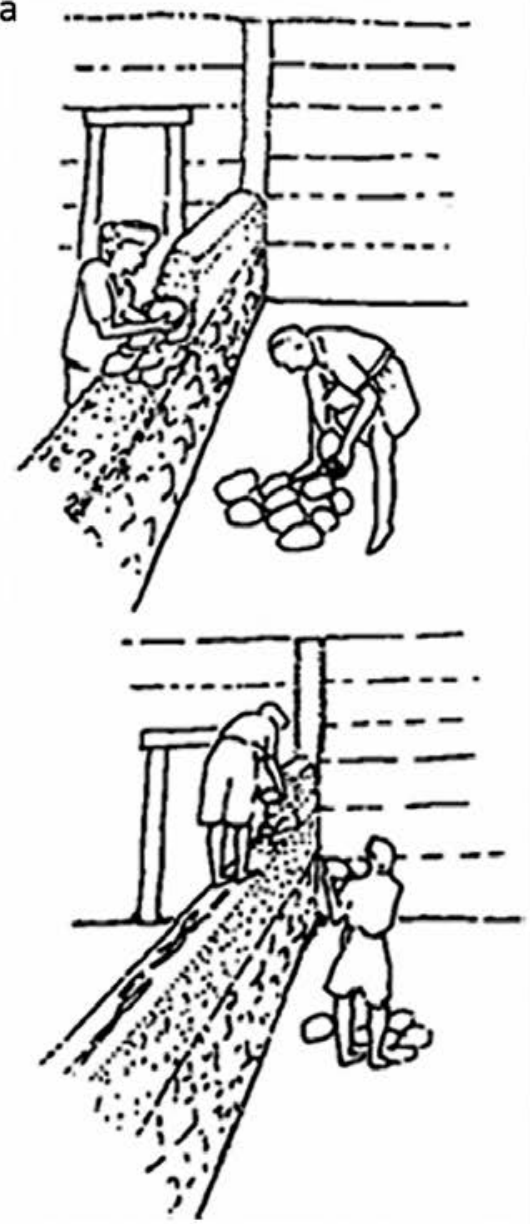

$\mathrm{b}$
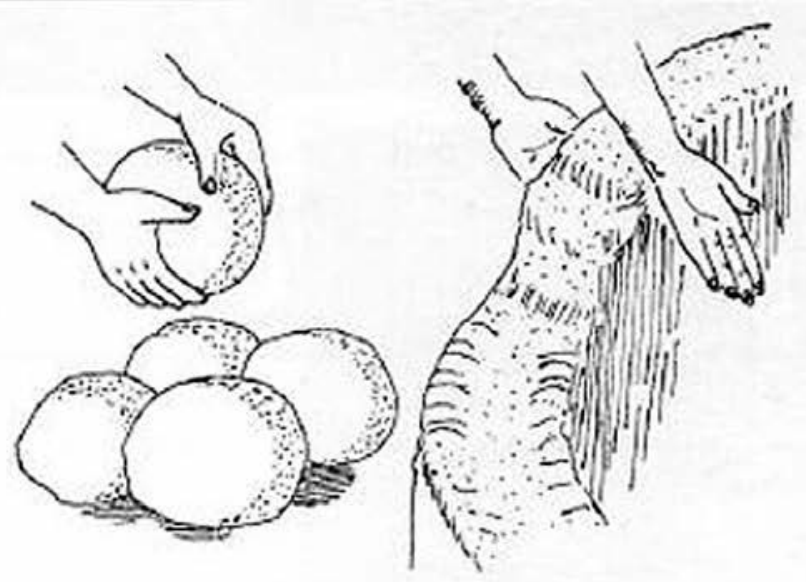

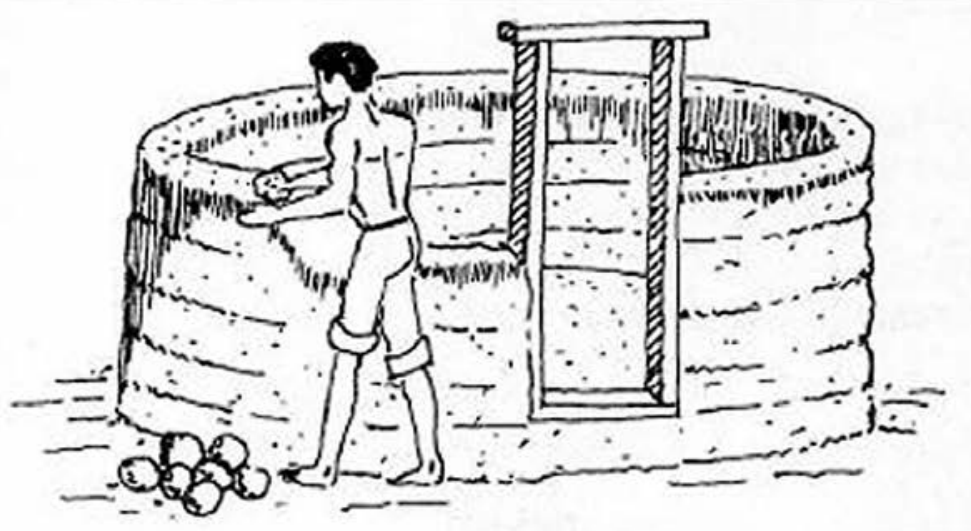

Figura 11. a. Construcción de un alzado mediante piezas de amasado de barro de forma oblonga (Wright, 1985, Fig. 297). b. Construcción con elementos de barro amasados de forma esférica (Minke, 2001: 87).

cuestión de mayor comodidad a la hora de transportar el material desde el espacio donde se ha realizado la mezcla hasta la construcción en curso. También se pueden utilizar para reparar determinadas partes de los muros donde sea necesario o para aplicar revestimientos de tierra, colocando las bolas unas junto a otras en las superficies verticales de los alzados (Dethier, 1982: 67, Fig. 19) (Fig. 12b), pudiendo ser después regularizado el barro y creando una superficie lisa. En los procesos de amasado del barro para tareas diversas, la ejecución de formas esféricas o semiesféricas es común, algo que puede verse, por ejemplo, en el amasado de arcilla para hacer cerámica (Rye, 1981: 4), pero también en la actividad productiva de rellenar manualmente moldes para realizar adobes. En los muros realizados mediante amasado de barro, tras aplicarse el material hasta alcanzar la altura deseada, se obtienen muros masivos, monolíticos, aunque con tendencia a la aparición de grietas de retracción (Minke, 2001). Con esta técnica pueden construirse también estructuras de actividad y almacenaje, como hornos y silos edificados (Guidoni, 1977: 250) (Fig. 12a).
Ya se aplique el barro de forma irregular o mediante formas esféricas, es común reservar un tiempo de secado entre hileras o a partir de una cierta altura (Baloi, 2001). Como en toda técnica de construcción con tierra, los alzados de amasado de barro pueden contar con zócalos de piedra. En otros ejemplos del empleo de esta técnica documentados en trabajos etnoarqueológicos (Agorsah, 1985: 105-106), los muros de amasado arrancan directamente del suelo y se emplean piedras alineadas en la base de los muros para tratar de proteger esta parte de las construcciones de diversos factores erosivos.

Con frecuencia, esta técnica emplea tierra de diferente granulometría, mezclada con agua y generalmente añadiendo, como material estabilizante, fibras vegetales como la paja de cereal u otros componentes orgánicos. Los procesos de estabilización (Bardou y Arzoumanian, 1978: 6; Houben y Guillaud, 1993; Guerrero, 2007; entre otros) tienen como objetivo mejorar el comportamiento constructivo de los morteros de barro, otorgándoles mayor resistencia ante distintos factores de alteración y, por tanto, mayor dura- 

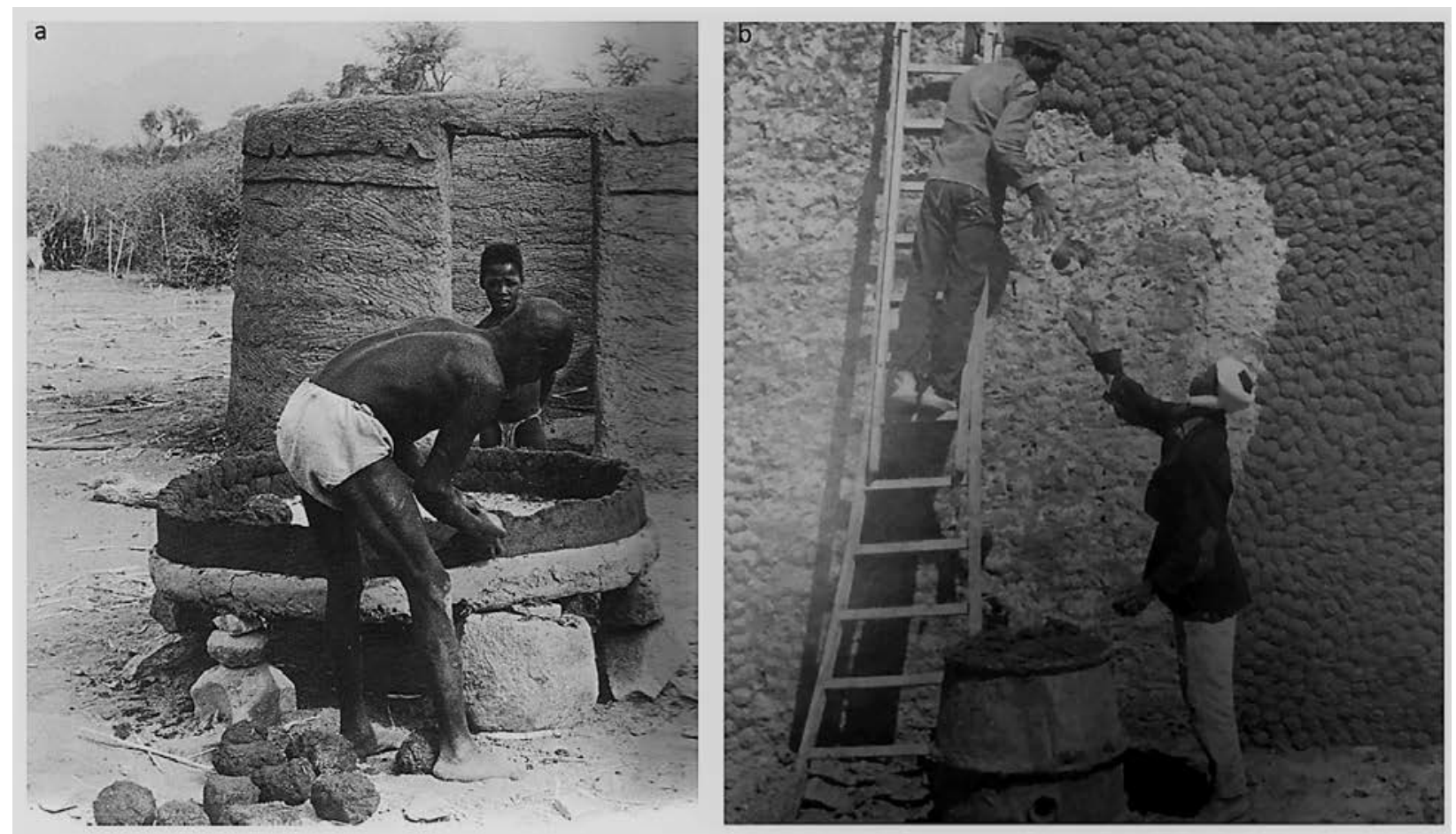

Figura 12. a. Construcción de un granero mediante la técnica del amasado en forma de bolas, Camerún (Guidoni, 1977: 250). b. Aplicación de un revestimiento mediante bolas de barro en el Sáhara argelino (Dethier, 1982: 67, Fig. 19).

bilidad. Al igual que en el caso de otras técnicas constructivas con tierra, en la construcción con amasado o amasado de bolas también se ha documentado el empleo de estiércol como estabilizante, para lo que, por el momento, conocemos ejemplos etnoarqueológicos (Morriss, 2000: 46; Baloi, 2001: 51) y el posible empleo de excrementos de ovicaprino en un amasado de barro empleado en el yacimiento de la Edad del Bronce de la cresta central del Cabezo del Polovar (Pastor, 2016; Jover et alii, 2016). El añadido de elementos vegetales también actúa como aglutinante. De hecho, el material vegetal en esta forma de construir no sólo puede añadirse a la mezcla que forma las bolas, sino que también pueden añadirse ramas entre las hileras, para reforzar la unión entre los materiales (Wright, 2009: 568, Fig. 325c). Además, se ha resaltado que el empleo de fibras vegetales contribuye a evitar el agrietamiento de los materiales constructivos de tierra, conduciendo la humedad hacia las superficies exteriores (Facey, 1997: 84).

Sin embargo, si las piezas de barro halladas en el asentamiento hubieran sido secadas previamente a su colocación, lo que no sería el caso de Caramoro I, nos habríamos encontrado ante el empleo de piezas o módulos de barro endurecido prefabricados, o "adobes" hechos a mano, sin molde. Estos adobes fabricados a mano se documentan en distintas regiones del mundo, como en el Perú prehispánico (Chirinos y Zárate, 2011) o en el Próximo Oriente antiguo, en asentamientos como Jericó, en Palestina, o Tepe Sialk, en Irán (Wright, 2009: 610-611), documentándose desde el XI milenio BC en asentamientos neolíticos pre-cerámicos de la zona del Levante del Próximo Oriente Asiático (Goring-Morris y BelferCohen, 2013: 21, 33). En estos territorios, dichas piezas suelen presentar una forma de tendencia rectangular, con una cara plana con marcas digitales y otra convexa (Aurenche, 1981: 60), y se fabrican generalmente en serie. En Irán, se han documentado bloques hechos a mano con formas diversas, denominadas "de barco" o "de hogaza" o "cigarro" - boat-shaped, hogbacked/cigar-shaped- en Ganj Dareh, Sheikh el Abad y Jani (Matthews, 2012: 201). No obstante, los adobes hechos a mano no han de ser necesariamente alargados, sino que pueden adoptar una forma cónica, semiesférica, etc. (Doat et alii, 1979: 106; Chirinos y Zárate, 2011: 42, 43). De hecho, se ha propuesto que la técnica constructiva del adobe hecho a mano podría derivar de la construcción en amasado de barro (Wright, 2009: 238).

Ambas técnicas, el amasado de barro en forma de bolas y el adobe, presentan procesos productivos distintos, a pesar de que los materiales necesarios para construir puedan ser prácticamente los mismos. En el amasado de bolas de barro, la mezcla se instala de manera directa tras su fabricación, por lo que es un proceso rápido. Las piezas que puedan hallarse en contexto arqueológico como resultado de esta mane- 
ra de colocar el barro presentarán un límite a su tamaño, marcado por la cantidad de mezcla que pueda manejarse con las manos y aplicarse a continuación en el muro en estado húmedo. Por el contrario, en el caso de las piezas secadas previamente antes de su empleo, se trataría de módulos prefabricados, preconcebidos y puestos en obra de un modo similar al de, por ejemplo, mampuestos o ladrillos, siendo generalmente unidos por un mortero. Esto implica una manera distinta de construir y de concebir la edificación de las estructuras, que requiere un proceso de mayor duración, una mayor inversión de energía y una serie de elementos añadidos respecto al caso anterior. Entre ellos, es necesario considerar los espacios físicos donde los adobes hechos a mano serían fabricados, donde se produciría el proceso de secado y, en su caso, también el almacenamiento. Además, estas piezas pueden también ser transportadas y esta manera de construir requeriría el transporte de los adobes, como mínimo desde su lugar de secado hasta la propia edificación en curso. Con todo ello, se requeriría probablemente un mayor número de personas implicadas en estos procesos constructivos. Como resultado, se generaría un producto diferente, que requiere conocimientos y habilidades específicos. Los adobes prefabricados a mano podrían realizarse con una mayor variedad de formas y, quizá también, de tamaños. En el caso de los adobes fabricados con molde, incluso se ha señalado que el tamaño podría alcanzar más de $1 \mathrm{~m}$ de longitud, como en el asentamiento neolítico de Çatalhöyük (Konya, Turquía) (Aurenche, 1981: 58; Stevanović, 2013: 98).

En cualquier caso, la identificación y diferenciación de estas técnicas a partir de las evidencias arqueológicas no es una cuestión sencilla, especialmente a partir del estudio de piezas individualizadas, aunque tampoco mediante la observación de restos conservados en contextos arqueológicos primarios. A nivel morfológico, su distinción es compleja en ambos casos, que pueden encontrarse con frecuencia afectados por procesos erosivos de forma considerable. En el caso de las evidencias de amasado en forma de bolas, determinar su procedimiento constructivo y, de este modo, la técnica a la que corresponden presenta dificultades respecto al adobe, pero también respecto a otras técnicas como el terrón, en la que los bloques se extraen directamente del suelo y son puestos en obra, sin desarrollarse una mezcla y conformación antrópica de las piezas. Teniendo en cuenta las dificultades de identificación, sobre todo si estos materiales no se encuentran en deposición primaria, no podría descartarse la posibilidad de que entre algunos de los elementos constructivos interpretados como adobes fabricados a mano, de diferentes formas, recogidos en las últimas décadas en distintos trabajos, puedan haberse hallado elementos resultantes de un amasado de barro.

Por su parte, la técnica del adobe hecho a molde es considerada la más fácilmente identificable entre el resto de técnicas constructivas con tierra (Arcelin y Buchsenschutz, 1985: 18; Belarte, 2002: 37), en comparación con técnicas mixtas como el bahareque, o de tierra masiva como el amasado o el tapial. No obstante, a nivel de distinción morfológica de los elementos individuales, por ejemplo, algunos adobes hechos a molde presentan formas convexas en su parte superior, resultado de una regularización manual de esta parte de las piezas en el molde. Por otro lado, el aspecto presentado por los alzados de "champas" o terrones, empleados en algunas construcciones prehispánicas, como en el caso de Huaca Ventarrón (Lambayeque, Perú) (Chirinos y Zárate, 2011: 51, 52), podría considerarse similar al de los elementos de barro amasados mediante la técnica constructiva que aquí abordamos.

\section{CONCLUSIONES}

Las evidencias presentadas en este trabajo muestran el empleo de una técnica constructiva apenas identificada hasta la fecha en el contexto de la Prehistoria reciente de la península ibérica. El uso de barro amasado y modelado en estado húmedo en forma de bolas y bloques se encuentra, por el momento, exclusivamente atestiguado para las sociedades argáricas en el reacondicionamiento de parte de los paramentos defensivos de este pequeño asentamiento argárico, Caramoro I, ubicado en el extremo septentrional de El Argar (González y Ruiz, 1995; Martínez Monleón, 2014). No ha sido documentado que esta técnica haya sido aplicada en otros alzados intramuros del poblado ni en la construcción de otro tipo de estructuras interiores presentes en las unidades de ocupación o habitación.

En este proceso constructivo se emplearon tierra no tamizada, agua y materia vegetal que no fue cortada o machacada en tramos más pequeños a la hora de ser añadida a la mezcla. Al parecer, al menos en una parte de los morteros constructivos de tierra, se reutilizaron sedimentos que contenían desechos, quizá de limpieza de espacios o estructuras utilizadas como hogares, lo que explicaría la presencia de ceni$\mathrm{za}$, huesos quemados y carbones en los materiales constructivos. En este sentido, conviene recordar que una práctica similar ya ha sido documentada en el caso de otro asentamiento argárico cercano, y en gran medida contemporáneo a Caramoro I, como es Cabezo Pardo (López, 2014), donde los análisis efectuados permitieron comprobar cómo los morteros de barro correspondientes a las construcciones de la 
fase II del asentamiento contenían restos reaprovechados de los "escombros" de las edificaciones de la fase constructiva anterior (Pastor, 2014: 322; Martínez Mira et alii, 2014: 373).

Por otro lado, a lo largo del texto también se ha tratado de poner de manifiesto la importancia del empleo adecuado de la terminología referente a la edificación con tierra, dadas las implicaciones que tiene para los avances y retrocesos de la investigación el uso impreciso e incorrecto de términos como "adobe". En general, aún hoy es frecuente encontrar en la bibliografía arqueológica expresiones tan vagas como las de "construcciones de material endeble" o "perecedero" para referirse a edificaciones realizadas, total o parcialmente, con tierra y madera, y no menos común es hallar la descripción de cualquier construcción muraria elaborada con tierra como "pared de adobe y tapial", un binomio tras cuyo erróneo significado han podido quedar invisibilizados otros ejemplos del uso de la técnica del amasado de barro en forma de bolas, en particular, pero también de otras técnicas de construcción con tierra. El caso de Caramoro I, donde la materialidad que evidencia el uso de la técnica constructiva que abordamos fue también publicada como adobes en un primer momento (González y Ruiz, 1995), es sólo un ejemplo de ello.

Esto puede deberse a una combinación de factores diversos, desde la escasa atención prestada tradicionalmente a los materiales constructivos de tierra y sus estructuras por parte de la arqueología, con el consiguiente desconocimiento que todavía existe acerca de las mismas, hasta las claras dificultades de su conservación e identificación en los contextos arqueológicos. En este sentido, a la hora de identificar, documentar y abordar el estudio de las formas y técnicas constructivas en el marco de la arqueología prehistórica, en nuestra opinión, debe ser una cuestión clave, en primer lugar, considerar la posibilidad de la propia existencia de prácticas constructivas tan poco conocidas como la que aquí se trata ya que, de no hacerlo, estas evidencias probablemente serán pasadas por alto. En segundo lugar, es necesario continuar abordando la definición, comparación y diferenciación arqueológica de las distintas técnicas de construcción con tierra puesto que, como hemos desarrollado en estas páginas, sus evidencias pueden adoptar formas muy similares entre sí que dificulten considerablemente su identificación, sobre todo si no se tienen en cuenta sus procesos de producción diferenciados. La posibilidad de distinguir correctamente estas cuestiones recae, en buena medida, en las labores de arqueología de campo y en quienes estudien en el laboratorio las evidencias recuperadas.
En el caso de Caramoro I, las excavaciones recientes en el asentamiento han sido fundamentales para poder determinar el empleo de la técnica del amasado de barro en forma de bolas y descartar la presencia de adobes. Estamos convencidos de que el número de hallazgos arqueológicos que evidencien esta técnica constructiva ha debido ser mayor al que en este momento podemos identificar con claridad, al haber podido ser obviados, no reconocidos o no publicados como tales. Esto sería aplicable no sólo a momentos argáricos, sino también, posiblemente, anteriores y posteriores, y esperamos que con el avance de esta línea de investigación pronto podamos asistir al reconocimiento de nuevos hallazgos en los que se documenten evidencias similares a las que aquí hemos presentado.

\section{AgRAdeCIMIENTOS}

Damos las gracias a A. González Prats y E. Ruiz Segura por proporcionarnos la planimetría efectuada durante sus excavaciones en el yacimiento, así como copia del diario de excavación. Asimismo, agradecemos al Museo Arqueológico y de Historia de Elche (MAHE), en especial a A. M. Álvarez Fortes, el habernos facilitado el acceso a los materiales arqueológicos analizados.

El presente trabajo ha sido realizado en el marco del proyecto de investigación "Espacios sociales y espacios de frontera durante el Calcolítico y la Edad del Bronce en el Levante de la península ibérica" (HAR2016-76586-P), financiado por el Ministerio de Economía y Competitividad del Gobierno de España.

\section{BIBLIOGRAFÍA}

Achenza, M., Sanna, U. (2008): Il manuale tematico della terra cruda, Interventi di trasferimento di Attività e Competenze Ambientali (ITACA). Cagliari-Sassani.

Agorsah, K. (1985): “Archaeological implications of traditional house construction among the Nchmuru of Northern Ghana". Current Anthropology 26, 1: 103-115. https://doi.org/10.1086/203230

Arcelin, P., Buchsenschutz, O. (1985): “Les données de la Protohistoire", en Lasfargues, J., Architectures de terre et bois, Documents d’Archeologie Francaise 2: 15-27, París.

Aurenche, O. (1981): La maison orientale. L'architecture du Proche Orient ancien des origines au milieu du Ivème millénaire, Tome 1, Institut Francais d'Archeologie du Proche Orient, París.

Ayala Juan, M. M., Ortiz González, R. (1989): "Análisis por difracción de rayos X de enlucidos de las casas argáricas de los yacimientos el Rincón de 
Almendricos y el Cerro de las Viñas de Coy, Lorca", Crónica del XIX Congreso Arqueológico Nacional (Castellón, 1987), 1, Universidad de Zaragoza, 323-328, Zaragoza.

Ayala Juan, M. M, Rivera Núñez, D., Obón De Castro, C. (1989): "Improntas vegetales de adobes procedentes de la casa A del yacimiento argárico en llanura de Rincón de Almendricos, Lorca, Murcia”, Crónica del XIX Congreso Arqueológico Nacional (Castellón, 1987) 1, Universidad de Zaragoza, 279291, Zaragoza.

Baloi, M.D.L. (2011): "Archaeology and mud wall decay in the Bowirba area: an ethnoarchaeological study". Pula: Botswana Journal of African Studies 15, 1: 46-59.

Bardel, P., Rioult, J.J. (2006): "Les premières formes de construction en bauge dans le bassin de Rennes", en Patte, E., Streiff, F., L'architecture en bauge en Europe. Actes du colloque européen organisé par le Parc naturel régional des Marais du Cotentin et du Bessin, Isigny-sur-Mer, 12-14 octobre 2006, Parc naturel régional des Marais du Cotentin et du Bessin, 151-171.

Bardou, P., Arzoumanian, V. (1978): Archi de terre. Marseille.

Bavay, G. (2006): “Trente années d'investigations sur la bauge en Wallonie (Belgique). La bauge dans le contexte des architectures de terre. Historiographie et tendances", en Patte, E., Streiff, F., L'architecture en bauge en Europe. Actes du colloque européen organisé par le Parc naturel régional des Marais du Cotentin et du Bessin, Isigny-sur-Mer, 12-14 octobre 2006, Parc naturel régional des Marais du Cotentin et du Bessin, 93-115.

Belarte Franco, M. C. (2002): La construcció amb terra a la protohistoria. Barcelona.

Bronk Ramsey, C. (2009): "Bayesian analysis of radiocarbon dates". Radiocarbon, 51 (1): 337-360. https://doi.org/10.1017/S0033822200033865

Burillo Mozota, F., Picazo Millán, J. (1986): El poblado del Bronce medio de la Hoya Quemada (Mora de Rubielos, Teruel), Seminario de Arqueología y Etnología turolense, Colegio Universitario de Teruel, Teruel.

Chirinos Cuadros, H., Zárate Aguinaga, E. (2011): Historia de la construcción en Lambayeque. Periodos prehispánico y Virreinal, Universidad Nacional de Ingeniería, Lima.

Correia, M. (2006): “A Universalidade e Diversidade da Arquitectura de Terra", en Correia, M., Oliveira Jorge, V. (eds.), TERRA: Forma de Construir. Arquitectura, Antropologia, Arqueologia, $10^{\text {a }}$ Mesa
Redonda de Primavera. FLUP, Universidade do Porto, 12-19, Lisboa.

De Chazelles, C. A, Klein, A., (dirs.) (2003): Échanges transdisciplinaires sur les constructions en terre crue, Actes de la table-ronde de Montpellier (17-18 novembre 2001), École d'architecture du Languedoc-Roussillon. Montpellier.

De Chazelles, C. A (2006): "La bauge dans les constructions du Languedoc et du Roussillon d'après les témoignages archéologiques du Néolithique à la fin du Moyen-Age. Essai de synthèse", en Patte, E., Streiff, F., L'architecture en bauge en Europe. Actes du colloque européen organisé par le Parc naturel régional des Marais du Cotentin et $d u$ Bessin, Isigny-sur-Mer, 12-14 octobre 2006, Parc naturel régional des Marais du Cotentin et du Bessin, 211-231.

Dethier, J. (1982): Mud architecture: an old idea, a new future. Down to earth. Londres.

Doat, P., Hays, A., Houben, H., Matuk, S., Vitoux, F. (1979): Construire en terre. París.

Facey, W. (1997): Back to earth: adobe building in Saudi Arabia. Londres.

García Borja, P., Carrión Marco, Y., Collado Beneyto, I., Montero Ruiz, I., Muñoz Abril, M., Pérez Jordá, G., Roldán García, C., Román Monroig, D., Tormo Cuñat, C., Verdasco Cebrián, C., Vives-Ferrándiz, J. (2010): "Campaña de excavación arqueológica de urgencia en Caramoro II (Elx, Alacant)". MARQ, Arqueología y Museos 4: 37-66.

González Prats, A., Ruiz Segura, E. (1992): “Un poblado fortificado del Bronce Final en el Bajo Vinalopó". Homenaje a Enrique Pla Ballester. 1727, Valencia.

González Prats, A., Ruiz Segura, E. (1995): "Urbanismo defensivo de la Edad del Bronce en el Bajo Vinalopó. La fortificación argárica de Caramoro I (Elche, Alicante)". Estudios de vida urbana, 85-105, Murcia.

Goring-Morris, A. N., Belfer-Cohen, A., (2013): "Houses and Households: a Near Eastern Perspective", en Hofmann, D., Smyth, J. (eds.), Tracking the Neolithic House in Europe, One World Archaeology, Springer Science-Business Media, 19-44, New York.

Guerrero Baca, L. F. (2007): “Arquitectura en tierra. Hacia la recuperación de una cultura constructiva". Apuntes 2, 2: 182-201.

Guidoni, E. (1977): Arquitectura primitiva. Madrid.

Güntzel, J. G. (1986): Zur Geschichte des Lehmbaus in Deutschland. Kassel. 
Gutherz, X., Jallot, L., Wattez, J., Borgnon, C., Roux, J.C., Thouvenot, Y., Orgeval, M. (2008): "L'habitat néolithique final de la Capoulière IV (Mauguio, Hérault): présentation des principaux résultats 2004-2007”, Actes 8e Rencontres Méridionales de Préhistoire Récente, Marseille.

Houben, H., Guillaud, H., (1993): Earth construction: a comprehensive guide. Dunsmore.

Jover Maestre, F. J., Martínez Monleón, S., Pastor Quiles, M., Poveda Hernández, E., López Padilla, J. A. (2016): "Los asentamientos de pequeño tamaño de la Edad del Bronce en tierras valencianas: A propósito del Cabezo del Polovar (Villena, Alicante)". Recerques del Museu d'Alcoi, 25: 47-68.

Keefe, L., (2005): Earth building. Methods and materials, repair and conservation. Oxon.

Klein, A. (2003): "La construction en terre crue par couches continues en Midi-Pyrénées. XVIe-XXe siècles. Contribution à l'identification des techniques", en De Chazelles, C. A., Klein, A., (dirs.), Échanges transdisciplinaires sur les constructions en terre crue, Actes de la table-ronde de Montpellier (17-18 novembre 2001), École d'architecture du Languedoc-Roussillon, Éditions de l'Espérou, 417-437, Montpellier.

Knoll, F., Klamm, M. (2015): Baustoff Lehm - seit Jahrtausenden bewährt. Archäologische, historische und rezente Zeugnisse des Lehmbaus. Ein Leitfaden für den Umgang mit "Rot- oder Hüttenlehm" im archäologischen Befund, Kleine Hefte zur Archäologie in Sachsen-Anhalt 12, Landesamt f. Denkmalpflege u. Archäologie Sachsen-Anhalt, Halle.

López Padilla, J. A. (coord.) (2014): Cabezo Pardo (San Isidro/ Granja de Rocamora, Alicante). Excavaciones arqueológicas en el yacimiento de la Edad del Bronce, Memorias Excavaciones Arqueológicas 6, Diputación de Alicante-Museo Arqueológico de Alicante (MARQ), Alicante.

Lull Santiago, V. (1983): La Cultura del Argar. Un modelo para el estudio de las formaciones económico-sociales prehistóricas. Madrid.

Lull Santiago, V., Micó Pérez, R., Rihuete Herrada, C., Risch, R. (2014): "The La Bastida fortification: new light and new questions on Early Bronze Age societies in the western Mediterranean". Antiquity 88: 395-410. https://doi.org/10.1017/S0003598 X00101073

Lull Santiago, V., Micó Pérez, R., Rihuete Herrada, C., Risch, R. (2015a): La Bastida y la Tira del Lienzo (Totana, Murcia). Ruta argárica 1. Guías arqueológicas. Integral, Sociedad para el desarrollo rural. ASOME-AUB. Murcia.
Lull Santiago, V., Micó Pérez, R., Rihuete Herrada, C., Risch, R. (2015b): "La gestión del agua durante El Argar: el caso de la Bastida (Totana, Murcia)". Minius, 23: 91-130.

Lull Santiago, V., Micó Pérez, R., Rihuete Herrada, C., Risch, R., Celdrán Beltrán, E., Fregeiro Morador, M.I., Oliart, C., Velasco Felipe, C. (2015c): La Almoloya (Pliego, Murcia). Ruta Argárica, Guías Arqueológicas 2. Integral, Sociedad para el Desarrollo Rural- Asome-UAB. Murcia.

Martínez Mira, I., Vilaplana Ortego, E., Such Basáñez, I., Juan Juan, J., García del Cura, M. A. (2014): "Cabezo Pardo. Análisis instrumental de materiales de construcción de barro del yacimiento argárico", en López Padilla, J. A. (coord.): Cabezo Pardo (San Isidro/Granja de Rocamora). Excavaciones arqueológicas en el yacimiento de la Edad del Bronce, MARQ Memorias Excavaciones Arqueológicas 6: 330-378, Alicante.

Martínez Monleón, S. (2014): El Argar en el Bajo Segura y Bajo Vinalopó. Patrón de asentamiento en un territorio de frontera. Fundación José María Soler, 23. Villena.

Matthews, W. (2012): "Defining households: Microcontextual analysis of Early Neolithic Households in the Zagros, Iran", en Parker, B. J., Foster, C. P., New Perspectives on household archaeology, Eisenbrauns. Winona Lake, Indiana:183-216.

Mileto, C., Vegas, F., Cristini, V., García, L. (2011): "Earthen techniques in Europe", en Terra Europae. Earthen Architecture in the European Union, ETS, Pisa, 195-203.

Minke, G. (2001): Manual de construcción en tierra. La tierra como material de construcción y su aplicación en la arquitectura actual. Montevideo.

Morriss, R. K. (2000): The archaeology of buildings. Stroud.

Mylona, P., Wattez, J., Franel, Y., Vigne, J-D. (2017): "L'utilisation de la terre crue au PPNA à Klimonas (Ayios Tychonas, Chypre): construction et évolution du bâtiment communautaire (structure 10). Approche géoarchéologique", en Vigne, J.D., Briois, F., Tengberg, M. (dirs.), Nouvelles données sur les débuts du Néolithique à Chypre, Séances de la Société Préhistorique Française 9, Paris, 105-118.

Pastor Quiles, M. (2014): “Cabezo Pardo. Contribución a las formas constructivas de un hábitat argárico a partir del estudio de los elementos de barro", en López Padilla, J. A. (coord.), Cabezo Pardo (San Isidro/ Granja de Rocamora, Alicante). Excavaciones arqueológicas en el yacimiento de la 
Edad del Bronce, Memorias Excavaciones Arqueológicas 6, Diputación de Alicante-Museo Arqueológico de Alicante (MARQ), 306-321, Alicante.

Pastor Quiles, M. (2016): "El estudio de los materiales constructivos de tierra del Cabezo del Polovar (Villena, Alicante): Aportación a las formas constructivas de dos pequeñas edificaciones campesinas de la Edad del Bronce en el Levante peninsular", Dama. Documentos de Arqueología y Patrimonio Histórico I, 25-39. https://doi.org/10.14198/dama.2016.1.03

Pastor Quiles, M. (2017): La construcción con tierra en arqueología. Teoría, método, técnicas y aplicación. Alicante.

Patte, E., Streiff, F. (2006): L'architecture en bauge en Europe. Actes du colloque européen organisé par le Parc naturel régional des Marais du Cotentin et du Bessin, Isigny-sur-Mer, 12-14 octobre 2006, Parc naturel régional des Marais du Cotentin et du Bessin.

Perello, B. (2015): "Pisé or not pisé? Problème de définition des techniques traditionnelles de la construction en terre sur les sites archéologiques", ArchéOrient - Le Blog (Hypotheses.org)

Ramos Fernández, R. (1988): “Caramoro: una fortaleza vigía de la Edad del Bronce”, Homenaje a Samuel de los Santos, 93-98, Albacete.

Reimer, P. J., Bard, E., Bayliss, A., Beck, J. W., Blackwell, P. G., Bronk, C., Buck, C. E., Cheng, H., Edwards, R. L., Friedrich, M., Grootes, P. M., Guilderson, T. P., Haflidason, H., Hajdas, I., Hatté, C., Heaton, T. J., Hoffmann, D. L., Hogg, A. G., Hughen, K. A., Kaiser, K. F., Kromer, B., Manning, S. W., Niu, M., Reimer, R. W., Richards, D. A., Scott, E. M., Southon, J. R., Staff, R. A., Turney, C. S. M., Van der Plicht, J. (2013): "IntCal13 and Marine13 Radiocarbon Age Calibration Curves 0-50,000 Years cal BP". Radiocarbon, $55 \quad$ (4): $1869-1887$. https://doi.org/10.2458/azu_js_rc.55.16947

Rivera Groennou, J. M. (2007): “Aproximación a las formas constructivas en una comunidad de la Edad del Bronce: El poblado argárico de Peñalosa (Baños de la Encina, Jaén)". Arqueología y territorio 4: 5-21.

Rivera Groennou, J. M. (2009): "Micromorfología e interpretación arqueológica: aportes desde el estudio de los restos constructivos de un yacimiento argárico en el Alto Guadalquivir, Peñalosa (Baños de la Encina, Jaén)”. Cuadernos de prehistoria y arqueología de la Universidad de Granada 19: 339-360.

Rivera Groennou, J. M. (2011): "Técnicas constructivas y relaciones sociales en una comunidad argárica del alto Guadalquivir, Peñalosa (Baños de la Encina, Jaén)", en Memorial Luis Siret, I Congreso de Prehistoria de Andalucía, La tutela del patrimonio prehistórico, Junta de Andalucía, Consejería de Cultura, 599-602, Sevilla.

Rotondaro, R. (2004): “Arquitectura y construcción con tierra en la Argentina. Tradiciones, alternativas y direcciones futuras", 1 er Seminario Construcción con Tierra FADU - UBA, 1-28.

Rye, O. S. (1981): Pottery Technology. Principles and reconstruction. Washington.

Sánchez García, A. (1997): "La problemática de las construcciones con tierra en la Prehistoria y Protohistoria peninsular. Estado de la cuestión", Actas del XXIII Congreso Nacional de Arqueología (Elche, 1995) 1, Ayuntamiento de Elche, 349-358, Elche.

Sánchez García, A. (1999): "Las técnicas constructivas con tierra en la arqueología prerromana del País Valenciano", Quaderns de Prehistòria i Arqueologia de Castelló 20: 161-188.

Scherrer, O. (2003): “Actualité de la construction en bauge en Afghanistan: la technique du "pakhsa", en De Chazelles, C. A., Klein, A., (dirs.), Échanges transdisciplinaires sur les constructions en terre crue, Actes de la table-ronde de Montpellier (17-18 novembre 2001), École d'architecture du Languedoc-Roussillon, Éditions de l'Espérou, 213-230, Montpellier.

Siret, L. y Siret, E. (1890): Las primeras edades del Metal en el sudeste de España. Barcelona.

Stevanović, M. (2013):" New Discoveries in House Construction at Çatalhöyük", en Hodder, I. (ed.) Substantive technologies at Çatalhöyük: reports from the 2000-2008 seasons. Çatal Research Project vol. 9. British Institute of Archaeology at Ankara, 48: 97-113.

Syrova, Z., Syrovy, J. (2006): "La bauge en Moravie dans le contexte des constructions historiques en terre crue de la région danubienne", en Patte, E., Streiff, F., L'architecture en bauge en Europe. Actes du colloque européen organisé par le Parc naturel régional des Marais du Cotentin et du Bessin, Isigny-sur-Mer, 12-14 octobre 2006, Parc naturel régional des Marais du Cotentin et du Bessin, 117-131.

Volkskundliche Kommission für Thüringen e.V (2009): Häuser aus Lehm und Stroh. Vergessene 
Bauweisen und Materialien, Hohenfeldener Hefte 4, Hohenfelden.

Wattez, J. (2003): "Enregistrement sédimentaire de l'usage de la terre crue dans les établissements néolithiques du Sud de la France: le cas des sites du Néolithique final de La Capoulière 2 et du Mas de Vignoles IV", en De la maison au village.
L'habitat néolithique dans le Sud de la France et le Nord-Ouest méditerranéen, Mémoire XLVIII de la Société Préhistorique française: 199-218.

Wright, G. R. H. (1985): Ancient Building in South Syria and Palestine. Leiden.

Wright, G. R. H. (2009): Ancient Building Technology, Vol. 3: Construction. Leiden 
